\title{
Multiple Sources of Striatal Inhibition Are Differentially Affected in Huntington's Disease Mouse Models
}

\author{
Carlos Cepeda, ${ }^{1 \star}$ Laurie Galvan, ${ }^{1 \star}$ Sandra M. Holley, ${ }^{1 \star}$ Shilpa P. Rao, ${ }^{1 \star}$ Véronique M. André, ${ }^{1}$ Elian P. Botelho, ${ }^{1}$ \\ Jane Y. Chen, ${ }^{1}$ Joseph B. Watson, ${ }^{1}$ Karl Deisseroth, ${ }^{2}$ and Michael S. Levine ${ }^{1}$ \\ ${ }^{1}$ Intellectual and Developmental Disabilities Research Center, Brain Research Institute, Semel Institute for Neuroscience, David Geffen School of Medicine, \\ University of California Los Angeles, Los Angeles, California 90095 and 2Departments of Bioengineering and Psychiatry and Behavioral Sciences, Stanford \\ University, Stanford, California 94305-2004
}

In Huntington's disease (HD) mouse models, spontaneous inhibitory synaptic activity is enhanced in a subpopulation of medium-sized spiny neurons (MSNs), which could dampen striatal output. We examined the potential source(s) of increased inhibition using electrophysiological and optogenetic methods to assess feedback and feedforward inhibition in two transgenic mouse models of HD. Single whole-cell patch-clamp recordings demonstrated that increased GABA synaptic activity impinges principally on indirect pathway MSNs. Dual patch recordings between MSNs demonstrated reduced connectivity between MSNs in HD mice. However, while connectivity was strictly unidirectional in controls, in HD mice bidirectional connectivity occurred. Other sources of increased GABA activity in MSNs also were identified. Dual patch recordings from fast spiking (FS) interneuron-MSN pairs demonstrated greater but variable amplitude responses in MSNs. In agreement, selective optogenetic stimulation of parvalbumin-expressing, FS interneurons induced significantly larger amplitude MSN responses in HD compared with control mice. While there were no differences in responses of MSNs evoked by activating single persistent low-threshold spiking (PLTS) interneurons in recorded pairs, these interneurons fired more action potentials in both HD models, providing another source for increased frequency of spontaneous GABA synaptic activity in MSNs. Selective optogenetic stimulation of somatostatin-expressing, PLTS interneurons did not reveal any significant differences in responses of MSNs in HD mice. These findings provide strong evidence that both feedforward and to a lesser extent feedback inhibition to MSNs in HD can potentially be sources for the increased GABA synaptic activity of indirect pathway MSNs.

\section{Introduction}

Huntington's disease (HD) is a devastating condition caused by an abnormal expansion of CAG repeats in the coding region of the HTT gene (The Huntington's Disease Collaborative Research Group, 1993). The principal striatal pathology in HD is degeneration of medium-sized spiny projection neurons (MSNs), while cholinergic and GABAergic interneurons are relatively spared (Vonsattel and DiFiglia, 1998). Genetic rodent models of HD (Mangiarini et al., 1996; Hodgson et al., 1999; Raymond et al., 2011) permit dissection of the principal steps of disease evolution. Although in mouse models there is little actual loss of MSNs, other neurodegenerative changes (e.g., spine and dendritic loss) are widespread (Klapstein et al., 2001; Laforet et al., 2001) and, more importantly, demonstrate that HD symptoms can occur in

Received April 23, 2012; revised March 18, 2013; accepted March 21, 2013.

Author contributions:V.M.A. and M.S.L. designed research;C.C., L.G., S.M.H., S.P.R., E.P.B., and J.B.W. performed research; K.D. contributed unpublished reagents/analytic tools; C.C., L.G., S.M.H., S.P.R., V.M.A., E.P.B., and J.Y.C. analyzed data; C.C. and M.S.L. wrote the paper.

This study was supported in part by United States Public Health Service NS 41574 and a contract with the Cure Huntington's Disease Initiative. We thank Donna Crandall for help with the illustrations.

${ }^{*}$ C.C., L.G., S.M.H., and S.P.R. contributed equally to this work.

The authors declare no competing financial interests.

Correspondence should be addressed to Dr. Michael S. Levine, IDDRC Room 58 -258, Semel Institute for Neuroscience and Human Behavior, UCLA School of Medicine, 760 Westwood Plaza, Los Angeles, CA 90095. E-mail: mlevine@mednet.ucla.edu.

DOI:10.1523/JNEUROSCI.2137-12.2013

Copyright $\odot 2013$ the authors $\quad 0270-6474 / 13 / 337393-14 \$ 15.00 / 0$ the absence of obvious cell loss (Tobin and Signer, 2000; Levine et al., 2004).

Alterations of synaptic activity in striatum and cerebral cortex have been demonstrated in HD models (Cepeda et al., 2007). Transient and progressive changes in spontaneous excitatory synaptic activity and biphasic changes in receptor sensitivity occur (Cepeda et al., 2003; Cummings et al., 2009; Graham et al., 2009; Joshi et al., 2009). In general, there is a progressive disconnection between cortex and striatum reflected by a reduction in spontaneous synaptic activity (Cepeda et al., 2003). In contrast, GABAergic synaptic activity is increased in a subset of MSNs (Cepeda et al., 2004; Centonze et al., 2005; Cummings et al., 2010; Dvorzhak et al., 2013). Upregulation of inhibitory synaptic activity, coupled with corticostriatal disconnection, could reduce striatal output to target regions (Cepeda et al., 2004), markedly altering information processing capability of MSNs.

While the progressive reduction of excitatory inputs can be explained by loss of presynaptic and postsynaptic markers (Cepeda et al., 2003, 2007), the source of increased GABA activity in MSNs remains unknown. Two types of GABAergic inhibition have been described in striatum; a feedback inhibition mediated by axon collaterals from MSNs themselves, and a feedforward inhibition generated by GABAergic interneurons (Tepper et al., 2004). Whereas the former appears to be relatively weak, the latter is strong and can regulate MSN firing (Tepper et al., 2004, 2008). Although the two types of inhibition have been extensively 
characterized in intact animals (Kawaguchi et al., 1995; Czubayko and Plenz, 2002; Tunstall et al., 2002; Plotkin et al., 2005; Kreitzer, 2009), little is known about the role of collateral MSN interactions and inhibitory interneurons in HD models.

Here we studied the potential origin of increased GABA synaptic activity in striatal slices from genetic mouse models of HD using single and dual patch-clamp recordings from MSNs and two types of GABAergic interneurons, the fast-spiking (FS) and the persistent low-threshold spiking (PLTS) interneurons. In addition, as direct and indirect pathway MSNs mediate different aspects of behavior and HD symptoms, we also examined selective changes in GABA synaptic activity in MSNs originating these pathways using mice that express enhanced green fluorescent protein (EGFP) under the control of the dopamine D1 (direct pathway) or D2 (indirect pathway) receptor promoters (Cepeda et al., 2008; André et al., 2011a,b). For selective activation of GABAergic interneurons we also used optogenetic methods (Tye and Deisseroth, 2012). We demonstrate that multiple sources contribute to increased GABAergic synaptic activity in HD mouse models and this increase impinges mainly on MSNs of the indirect pathway.

\section{Materials and Methods}

Animals. All experimental procedures were performed in accordance with the United States Public Health Service Guide for Care and Use of Laboratory Animals and were approved by the Institutional Animal Care and Use Committee at the University of California, Los Angeles (UCLA). Every effort was made to minimize pain and discomfort. R6/2 transgenic mice and wild-type (WT) littermates were obtained from our colony at UCLA. These mice were maintained by crossing WT male C57BL/6xCBA mice with WT female C57BL/6xCBA mice that had transplanted R6/2 ovaries (both males and females purchased from The Jackson Laboratory). All mice were genotyped twice, once at weaning and again after the electrophysiological recordings. R6/2 mice had a range of 104-124 CAG repeats. The mean CAG repeat length was $116.8 \pm 1.1$ ( $n=31$ animals). Animals were used at three ages: $21-30 \mathrm{~d}$ (before the onset of overt behavioral symptoms, $<30 \mathrm{~d}$ group), $30-60 \mathrm{~d}$ (overt behavioral phenotype begins, $30-60 \mathrm{~d}$ group), and $60-80 \mathrm{~d}$ (full behavioral phenotype, $>60 \mathrm{~d}$ group). Some experiments were performed on R6/2 mice crossed with C57BL/6 mice expressing EGFP under the control of the promoter for either dopamine D1 or D2 receptors. Experiments also were performed on a second mouse model of $\mathrm{HD}$ (FVB/N strain) that carried full-length human mutant $H T T$ gene, with $97 \mathrm{CAG}$ repeats, on a bacterial artificial chromosome (BACHD) (Gray et al., 2008). BACHD and WT littermates from our colonies at UCLA were crossbred with heterozygous $\mathrm{FVB} / \mathrm{N}$ mice expressing EGFP under control of the D1 or D2 promoter. For some experiments we also used R6/2 and BACHD mice crossbred with heterozygous $\mathrm{FVB} / \mathrm{N}$ mice expressing EGFP under the control of Lhx6 promoter to more easily identify striatal interneurons. Lhx6 is expressed by cells that develop into parvalbumin (PV)-, somatostatin (SOM)-, calretinin-, and neuropeptide Y (NPY)-expressing interneurons in the striatum (Marin et al., 2000; Kreitzer, 2009). BACHD mice were used at 2 and 12 months of age. R6/2 mice were symptomatic $(>60$ d) and the CAG repeat length was 150-166. We have shown previously that mice with 110-120 CAG repeats display similar phenotype as the original R6/2 mice with $\sim 150$ repeats (Cummings et al., 2012).

Cell visualization and electrophysiology. Detailed procedures have been published (Cepeda et al., 2008; André et al., 2011b). Briefly, mice were deeply anesthetized with isoflurane and killed. The brain was rapidly removed and placed in ice-cold low- $\mathrm{Ca}^{2+}$ artificial CSF (ACSF) containing the following (in mM): $130 \mathrm{NaCl}, 3 \mathrm{KCl}, 1.25 \mathrm{NaH}_{2} \mathrm{PO}_{4}, 26 \mathrm{NaHCO}_{3}$, $5 \mathrm{MgCl}_{2}, 1 \mathrm{CaCl}_{2}$, and 10 glucose. Coronal slices were cut $(350 \mu \mathrm{m})$ using a microslicer (Leica VT1000S; Leica Microsystems) and transferred to an incubating chamber containing ACSF (with $2 \mathrm{~mm} \mathrm{CaCl}_{2}$ and $2 \mathrm{~mm}$ $\mathrm{MgCl}_{2}$ ) oxygenated with $95 \% \mathrm{O}_{2}-5 \% \mathrm{CO}_{2}$ ( $\mathrm{pH} 7.2-7.4,290-310$ mOsm) and recordings started after at least $1 \mathrm{~h}$ incubation at room temperature.
The microscope (Olympus BX51WI) was equipped with differential interference contrast optics and fluorescence.

Whole-cell patch-clamp recordings in voltage and current-clamp modes were obtained from neurons using a MultiClamp 700B Amplifier (Molecular Devices) and pCLAMP 10.2. The patch pipette (3-5 M $\Omega$ resistance) contained a high $\mathrm{Cl}^{-}$solution (in mM): $140 \mathrm{CsCl}, 10 \mathrm{HEPES}-$ $\mathrm{Na}, 10$ EGTA, $2 \mathrm{MgCl}_{2}$, and $1 \mathrm{CaCl}_{2}$ (pH 7.2 with $\mathrm{CsOH}, 270 \mathrm{mOsm}$ ) for voltage-clamp recordings or a $\mathrm{K}$-gluconate-based high $\mathrm{Cl}^{-}$solution containing the following (in $\mathrm{mM}$ ): $60 \mathrm{~K}$-gluconate, $58 \mathrm{KCl}, 10 \mathrm{NaCl}, 1 \mathrm{MgCl}_{2}$, 10 HEPES-Na, $2 \mathrm{Na}_{2}$-ATP, $0.1 \mathrm{Na}$-GTP, 2 phosphocreatine, 0.1 leupeptin, and 0.5 EGTA (pH 7.2 with $\mathrm{KOH}$ or $\mathrm{KCl}, 270 \mathrm{mOsm}$ ) for currentclamp recordings. Both internal solutions had a high $\mathrm{Cl}^{-}$concentration (reversal potential $\sim 0 \mathrm{mV}$ ) for better resolution of GABAergic events/ responses at the resting membrane potential (RMP). For some voltageclamp recordings a Cs-methanesulfonate-based internal solution without high $\mathrm{Cl}^{-}$was used containing the following (in mM): $130 \mathrm{Cs}$ methanesulfonate, $10 \mathrm{CsCl}, 4 \mathrm{NaCl}, 1 \mathrm{MgCl}_{2}, 5 \mathrm{MgATP}, 5$ EGTA, 10 HEPES, 5 GTP, 10 phosphocreatine, and 0.1 leupeptin. Electrode access resistances were $<25 \mathrm{M} \Omega$.

Spontaneous postsynaptic currents (PSCs) were recorded in gap-free mode at room temperature in standard ACSF. Membrane current was filtered at $1 \mathrm{kHz}$ and digitized at $100 \mu$ s using Clampex 10.2. Glutamate receptor antagonists 6-cyano-7-nitroquinoxaline-2,3-dione (CNQX, 10 $\mu \mathrm{M})$ and D-2-amino-5-phosphonovaleric acid (AP-5, $50 \mu \mathrm{M})$ were included in the external solution when recording GABAergic postsynaptic events. In some experiments, tetrodotoxin (TTX, $1 \mu \mathrm{M}$ ) and CGP 54626 hydrochloride $\left(\mathrm{GABA}_{\mathrm{B}}\right.$ receptor antagonist) were included in the external solution along with CNQX and AP-5. Tonic GABA currents were measured as the steady-state currents blocked by bicuculline methiodide (BIC, $20 \mu \mathrm{M}$ ).

Synaptic stimulation. To evoke synaptic currents, a monopolar stimulating electrode (glass-pipette filled with ACSF, impedance $\sim 1.5 \mathrm{M} \Omega$ ) was placed in the striatum $300-400 \mu \mathrm{m}$ from the recorded cell. QX-314 $(4 \mathrm{~mm})$ was included in the pipette solution and IPSCs were evoked with neurons voltage-clamped at $-70 \mathrm{mV}$ in the presence of CNQX $(10 \mu \mathrm{M})$ and AP-5 $(50 \mu \mathrm{M})$. Test stimuli $(0.5 \mathrm{~ms}$ duration $)$ were applied every $20 \mathrm{~s}$ and responses were averaged over three consecutive trials. Test stimuli were applied at increasing stimulus intensities $(0.002-0.012 \mathrm{~mA})$ to assess input-output functions. For paired-pulse stimulation, intensities were set to evoke responses at $30 \%$ of maximal amplitude. Paired-pulse ratios (PPRs) were determined (peak amplitude pulse 2/peak amplitude pulse 1) to examine changes in probability of release at intervals between 25 and $800 \mathrm{~ms}$.

Dual recordings from striatal neurons. Simultaneous whole-cell patchclamp recordings were made from morphologically identified pairs of neurons not $>50 \mu \mathrm{m}$ apart and at the same depth from the surface of the slice (same focal plane). After dual whole-cell recording was established in voltage-clamp mode and passive membrane properties were recorded, both neurons were switched to current-clamp mode (zero current) and the RMPs noted. Synaptic connectivity between pairs of neurons was determined by injecting depolarizing current in one neuron to evoke action potential firing and recording the response in the second neuron. The protocol was repeated in reverse to determine whether the connection was reciprocal. Two types of depolarizing current steps were used: a short pulse of $20 \mathrm{~ms}(100-300 \mathrm{pA})$ that evoked a single action potential in the presynaptic neuron and a long current pulse (1000 ms, 50-200 pA) that evoked a train of action potentials $(15-20 \mathrm{~Hz})$, except in the case of PLTS interneurons, which displayed action potential adaptation when high intensity current pulses were used. Responses to the action potentials were defined as postsynaptic events with amplitudes $>0.3 \mathrm{mV}$ (three times the SD of the baseline noise) that occurred within $4 \mathrm{~ms}$ of the peak of the action potential (Tunstall et al., 2002). Responses to 150-200 action potentials per pair were examined to obtain the success rate for each connection (the number of action potentials that evoked a response in the postsynaptic neuron converted to the percentage of the total number of action potentials tested). A pair of neurons was defined as connected only when the success rate of the connection was $>10 \%$. While traditionally a pair of MSNs was considered as two potential connections (Tunstall et al., 2002; Koós et al., 2004), we calculated connected pairs as 
only one connection due to that fact that bidirectional connectivity only occurred exceptionally, at least in WT animals. A similar calculation was used for interneuron-MSN pairs. Thus, regardless of cell type, one connected pair of 10 recorded pairs represented $10 \%$ connectivity. To characterize postsynaptic potentials (PSPs), the amplitude, rise time, decay time, and area were measured from averages of $\sim 5-10$ responses.

Optogenetic stimulation of striatal interneurons. We used optogenetic techniques to activate selectively GABAergic interneurons to determine their relative contribution to GABA synaptic activity in MSNs. FS interneurons express PV and PLTS interneurons express diverse peptides and enzymes including SOM, NPY, and nitric oxide (NO) synthase (Kawaguchi et al., 1995). The excitatory opsin, channelrhodopsin-2 (ChR2) and its reporter gene enhanced yellow fluorescent protein (EYFP) were inserted in a doublefloxed inverted open reading frame viral vector (AAV2-DIO-ChR2-EYFP) (Gene Transfer Vector Core, University of Iowa, Iowa City, IA). AAV2-DIOChR2-EYFP was stereotaxically injected into the striatum of 1-month-old WT and R6/2 mice crossed with $P V:: C r e$ and SOM::Cre mice (C57BL/6J background) $\left(1 \mu \mathrm{l} / \mathrm{site}, 9.45 \times 10^{9} \mathrm{vg} / \mu \mathrm{l}, 0.2 \mu \mathrm{l} / \mathrm{min}\right)$ using the following coordinates: $1.0 \mathrm{~mm}$ anterior and $2.0 \mathrm{~mm}$ lateral to bregma, at a depth of 3.3 $\mathrm{mm}$ from the dura, the tooth bar was set at $0 \mathrm{~mm}$. After Cre recombination, ChR2-EYFP is selectively expressed in PV::Cre or SOM::Cre neurons in the mice. The expression of these proteins was visualized by EYFP fluorescence. Sections also were stained for PV (rabbit antibody-PV28, Swant, 1/250 dilution; secondary antibody, anti-rabbit-Alexa594, Invitrogen) and examined for colocalized EYFP-positive cells to demonstrate the construct was only expressed in PV interneurons. SOM-EYFP cells were similarly identified. MSNs were recorded in voltage-clamp mode using Cs-methanesulfonate as the internal solution. This solution also contained biocytin $(0.2 \%)$ for subsequent cell identification. At $+10 \mathrm{mV}$ holding potential, a brief LED (CoolLED) pulse ( $470 \mathrm{~nm}, 0.5 \mathrm{~ms}, 8 \mathrm{~mW}$ ) stimulated the network of ChR2EYFP interneurons surrounding the patched MSNs in the slice. All experiments comparing MSN responses from WT and R6/2 mice used the same intensity and duration of the light stimulus. Yellow light was used as control stimulation ( $585 \mathrm{~nm}, 0.5 \mathrm{~ms}, 2 \mathrm{~mW}$ ).

Drugs. Stocks of AP-5, BIC (Tocris Bioscience), CNQX (Sigma), and TTX (Calbiochem) were dissolved in water. QX-314 (Sigma) was dissolved in the appropriate pipette internal solution. CGP 54626 (Tocris Bioscience) was dissolved in dimethylsulfoxide to make stock solution and the final concentration did not exceed $0.1 \%$. During the experiment, stock solutions were added to the perfusate at the desired concentration.

Data analysis and statistics. Data are reported as mean \pm SEM. Statistical analyses were performed using Student's $t$ test for two group comparisons, one-way ANOVA followed by appropriate post hoc tests for three or more group comparisons, and $\chi^{2}$ test for distributions. Cumulative distributions were compared using Kolmogorov-Smirnov (K-S) test or one or two-way appropriately designed ANOVAs and Bonferroni post hoc tests. Differences were considered statistically significant if $p<$ 0.05 . Spontaneous synaptic currents were analyzed off-line using the automatic detection protocol within the Mini Analysis Program (Justin Lee, Synaptosoft, 1999) and subsequently checked manually for accuracy. Event analyses were performed blind to genotype. Analyses of individual postsynaptic responses obtained during dual patch recordings were performed using the Mini Analysis Program.

\section{Results}

Spontaneous $\mathrm{GABA}_{\mathrm{A}}$ receptor-mediated synaptic currents are increased in symptomatic R6/2 mice

We and others have shown that the frequency of spontaneous GABAergic synaptic currents is increased in MSNs from R6/2 (Cepeda et al., 2004; Centonze et al., 2005; Dvorzhak et al., 2013) and other mouse models (Cummings et al., 2010; Dvorzhak et al., 2013). In our original studies we used a Cs-methanesulfonatebased pipette solution and held the membrane at $+10 \mathrm{mV}$. To minimize potential adverse effects of prolonged membrane depolarization, in the present experiment we used a high- $\mathrm{Cl}^{-}$internal solution to maintain the membrane at $-70 \mathrm{mV}$ and to increase the driving force of $\mathrm{Cl}^{-}$channels (calculated GABA reversal potential was $\sim 0 \mathrm{mV}$ ). Consistent with previous studies
Table 1. Basic membrane properties in mice

\begin{tabular}{|c|c|c|c|}
\hline & $\mathrm{Cm}(\mathrm{pF})$ & $\mathrm{Rm}(\mathrm{M} \Omega)$ & tau (ms) \\
\hline \multicolumn{4}{|c|}{ Basic cell membrane properties in $\mathrm{R} 6 / 2$ mice } \\
\hline \multicolumn{4}{|l|}{ MSNs } \\
\hline WT $(n=16)$ & $84.6 \pm 5.1$ & $144.6 \pm 26.6$ & $3.7 \pm 0.4$ \\
\hline $\mathrm{R} 6 / 2(n=22)$ & $65.0 \pm 3.8^{* *}$ & $258.3 \pm 530.7^{* *}$ & $2.1 \pm 0.2^{* *}$ \\
\hline \multicolumn{4}{|l|}{ FS } \\
\hline WT $(n=16)$ & $48.5 \pm 4.1$ & $172 \pm 23$ & $1.4 \pm 0.1$ \\
\hline $\mathrm{R} 6 / 2(n=6)$ & $49.5 \pm 7.3$ & $181 \pm 25$ & $1.9 \pm 0.4$ \\
\hline \multicolumn{4}{|l|}{ PLTS } \\
\hline WT $(n=29)$ & $43.2 \pm 2.6$ & $824 \pm 86$ & $1.2 \pm 0.2$ \\
\hline $\mathrm{R} 6 / 2(n=36)$ & $44.5 \pm 2.7$ & $1014 \pm 98$ & $1.5 \pm 0.2$ \\
\hline \multicolumn{4}{|c|}{$\begin{array}{l}\text { Basic membrane properties of interneurons } \\
\text { in BAC mice }\end{array}$} \\
\hline \multicolumn{4}{|l|}{ FS } \\
\hline \multicolumn{4}{|l|}{ (2 months) } \\
\hline $\mathrm{WT}(n=3)$ & $28.3 \pm 5.2$ & $167.3 \pm 47.4$ & $0.8 \pm 0.5$ \\
\hline $\mathrm{BAC}(n=4)$ & $37.0 \pm 15$ & $102.8 \pm 35.6$ & $0.6 \pm 0.2$ \\
\hline \multicolumn{4}{|l|}{ (12 months) } \\
\hline $\mathrm{WT}(n=5)$ & $28.2 \pm 7.5$ & $128.8 \pm 28.3$ & $1.1 \pm 0.3$ \\
\hline $\mathrm{BAC}(n=3)$ & $25.3 \pm 5.4$ & $49.7 \pm 20.5$ & $0.6 \pm 0.2$ \\
\hline \multicolumn{4}{|l|}{ PLTS } \\
\hline \multicolumn{4}{|l|}{ (2 months) } \\
\hline $\mathrm{WT}(n=5)$ & $39.9 \pm 9.0$ & $1349 \pm 357$ & $1.7 \pm 0.3$ \\
\hline $\mathrm{BAC}(n=7)$ & $37.2 \pm 5.9$ & $1347 \pm 348$ & $1.4 \pm 0.2$ \\
\hline \multicolumn{4}{|l|}{ (12 months) } \\
\hline $\mathrm{WT}(n=8)$ & $43.3 \pm 4.7$ & $1721 \pm 271$ & $1.0 \pm 0.1$ \\
\hline $\mathrm{BAC}(n=7)$ & $37.0 \pm 3.8$ & $1420 \pm 280$ & $1.0 \pm 0.1$ \\
\hline
\end{tabular}

$B A C$, bacterial artificial chromosome; $C \mathrm{~m}$, cell membrane capacitance; $\mathrm{Rm}$, input resistance; tau, time constant. ${ }^{* *}$ Difference statistically significant at $p<0.01$.

(Klapstein et al., 2001; Cepeda et al., 2003; Cummings et al., 2010), basic membrane properties were significantly different in WT $(n=16$, aged $49 \pm 2 \mathrm{~d})$ and $\operatorname{R} 6 / 2(n=22$, aged $51 \pm 3 \mathrm{~d})$ mice. Cell capacitance was decreased, membrane input resistance was higher, and the time constant was faster in R6/2 transgenics compared with WT mice (Table 1). Similarly, MSNs from R6/2 mice had a higher mean IPSC frequency compared with WT $(2.2 \pm 0.4 \mathrm{~Hz}, n=16$ in WT, $5.8 \pm 0.7 \mathrm{~Hz}, n=22$ in $\mathrm{R} 6 / 2 ; p<$ 0.001 ) (Fig. 1A). These spontaneous (s)IPSCs were mediated by activation of $\mathrm{GABA}_{\mathrm{A}}$ receptors as they could be completely blocked by application of BIC $(10 \mu \mathrm{M})$ (Fig. $1 A)$. The amplitudefrequency histogram revealed a significant increase in frequency of events across all amplitude bins with the largest increase in the $50-100$ pA amplitude bin (Fig. 1A). Probability distributions of cumulative interevent intervals were significantly $(p<0.001$, $\mathrm{K}-\mathrm{S}$ test) shifted to the left in MSNs from R6/2 mice indicating more frequent events. In addition, the sIPSC average amplitude (events in the 10-100 pA range) was significantly larger in R6/2 MSNs compared with WT $(-21.9 \pm 1.1 \mathrm{pA}$ in WT, $-27.2 \pm 1.4$ $\mathrm{pA}$ in $\mathrm{R} 6 / 2 ; p<0.05)$.

\section{Increased GABA synaptic activity affects mainly D2 receptor-expressing MSNs}

Previously, we demonstrated the existence of two populations of MSNs in R6/2 mice, one with increased GABA synaptic activity and the other with GABA activity more similar to that of WTs (Cepeda et al., 2004). To assess whether there were differential changes in the frequency of sIPSCs between direct and indirect pathway MSNs, we recorded from symptomatic R6/2 mice crossed with D1-EGFP and D2-EGFP mice and compared the results from recordings in similarly crossed WT littermate controls. Although there was a trend for direct pathway MSNs from $\mathrm{R} 6 / 2$ mice to display increased mean sIPSC frequency compared 
with WTs, the difference was not statistically significant $(1.9 \pm 0.6 \mathrm{~Hz}, n=5$, age $52 \pm 3 \mathrm{~d}$ in WT and $3.7 \pm 0.9 \mathrm{~Hz}, n=6$, age $55 \pm 5 \mathrm{~d}$ in R6/2) (Fig. $1 B$, left graph). In contrast, D2 MSNs in R6/2 mice showed a robust increase in the frequency of spontaneous GABAergic events in all bins (mean frequency $1.5 \pm 0.3 \mathrm{~Hz}, n=7$, age $57 \pm 0.3 \mathrm{~d}$ in WT and $4.9 \pm 1 \mathrm{~Hz}, n=$ 7 , age $59 \pm 5 \mathrm{~d}$ in $\mathrm{R} 6 / 2, p<0.01$ ) (Fig. $1 B$, right graph). The cumulative probability distributions indicated that there was a significant difference in distributions of interevent intervals in both D1 $(p<0.05)$ and D2 $(p<0.001)$ MSNs in R6/2 mice when compared with those from WTs (K-S test) (Fig. 1C). However, while the cumulative probability distributions from R6/2 compared with WT D1 MSNs differed only marginally, there was a clear difference in the distributions from R6/2 compared with WT D2 MSNs indicating that the increase in GABA activity affects mostly MSNs of the indirect pathway. Also, as previously shown (Cepeda et al., 2004), there was no significant difference in the mean frequency of miniature IPSCs (mIPSCs) recorded from MSNs in the presence of TTX $(0.89 \pm 0.2 \mathrm{~Hz}, n=11$ in $\mathrm{R} 6 / 2 ; 0.80 \pm 0.2 \mathrm{~Hz}, n=6$ in WT), suggesting that the primary source of increased inhibitory input to MSNs is activity dependent and likely presynaptic.

\section{Tonic GABA currents in $\mathrm{R} 6 / 2$ mice are reduced}

We also examined potential differences in tonic $\mathrm{GABA}_{\mathrm{A}}$ currents in R6/2 mice crossed with D1-EGFP or D2-EGFP mice. Application of BIC $(20 \mu \mathrm{M})$ in the presence of glutamate (10 $\mu \mathrm{M}$ CNQX and $50 \mu \mathrm{M}$ AP-5) and $\mathrm{GABA}_{\mathrm{B}}(1 \mu \mathrm{M}$ CGP 54626) receptor antagonists induced a shift in the holding current in MSNs. This shift reflects the amount of tonic GABA current (Brickley and Mody, 2012). As shown by others (Santhakumar et al., 2010), tonic GABA currents were greater in D1-expressing compared with D2expressing MSNs from WT animals (Fig. 2). Tonic GABA currents were similar in D1-expressing MSNs from WT and R6/2 mice. However, they were significantly reduced in D2-expressing MSNs from R6/2 mice ( $p<0.001)$ (Fig. $2)$. No significant differences in tonic GABA currents were observed between MSNs from WT (15.7 $\pm 4.7 \mathrm{pA}, n=7)$ and R6/2 $(16.3 \pm 6.5 \mathrm{pA}, n=4)$ mice when TTX $(1 \mu \mathrm{M})$ was added indicating the difference was action potential dependent (data not shown).

\section{Evoked GABA synaptic activity is increased in R6/2 mice}

To examine in more detail the changes in GABAergic synaptic responses, we compared evoked GABA currents in MSNs from $\mathrm{R} 6 / 2$ mice and WT littermates. IPSCs were evoked by intrastriatal
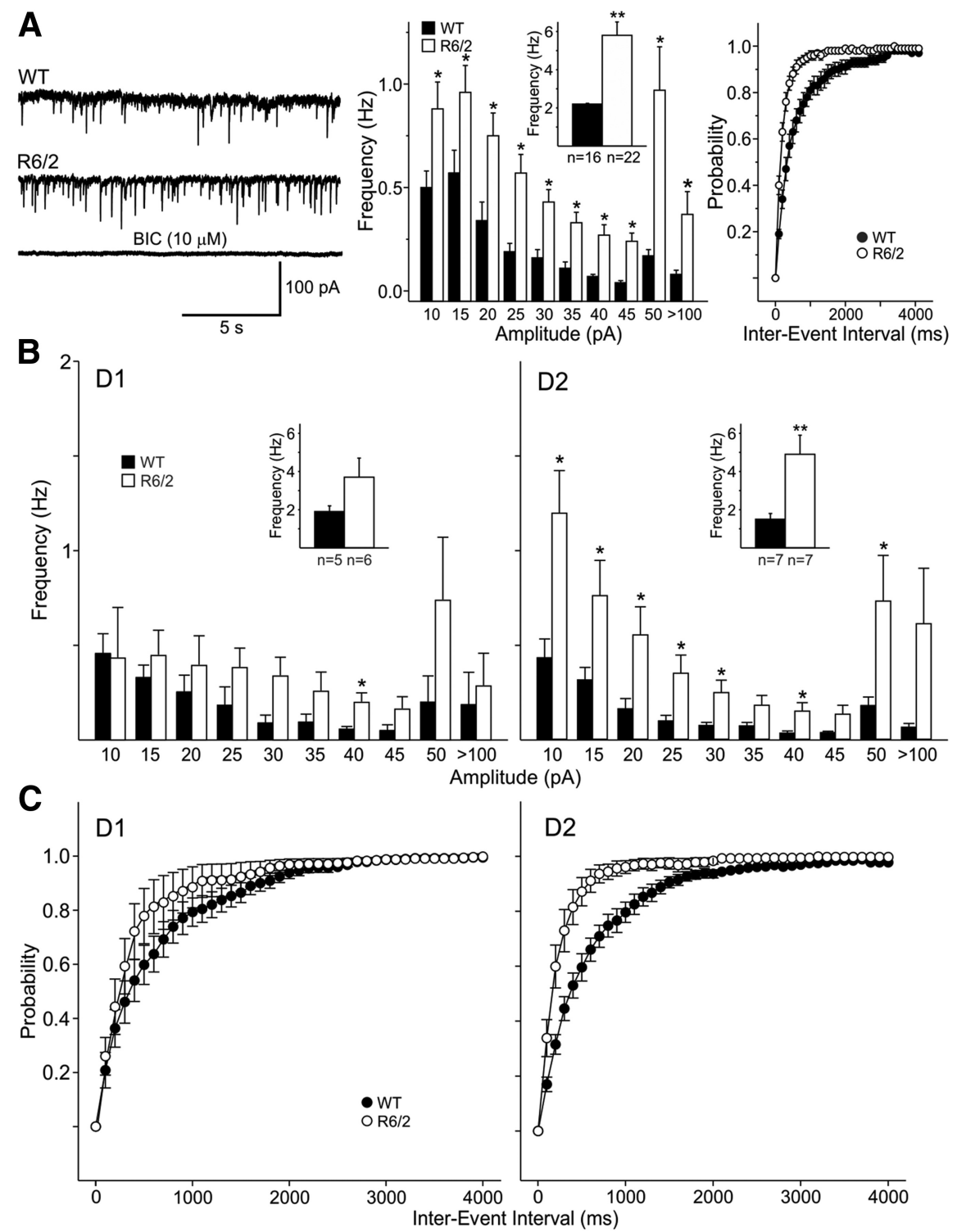

Figure 1. A, Traces show sIPSCs from WT and R6/2 MSNs (CsCl internal solution, $-70 \mathrm{mV}$ holding potential, CNQX, and AP-5 present). Bottom trace shows that BIC (10 $\mu \mathrm{m})$ blocked the inward currents demonstrating they were mediated by activation of $G A B A_{A}$ receptors. The middle graph shows that amplitude-frequency histograms had significantly increased frequencies of events across all amplitude bins, with the largest increase in the 50-100 pA bin. Inset shows mean frequencies. Right graphs show in MSNs from R6/2 mice (proportionately more events with shorter intervals in MSNs) ( $p<0.001$, K-S test). $\boldsymbol{B}$, Amplitudeequency histograms indicate that, although there was a trend, D1-MSNs did not show significantly different frequencies of events 列, except for the $40 \mathrm{pA}$ amplitude bin. In contrast, D2-MSNs in R6/2 mice showed significant increases at all amplitude bins except the largest amplitude bin. $C$, The cumulative interevent interval probability distributions indicated that there was a significant difference in interevent intervals in D1 ( $p<0.05, \mathrm{~K}-\mathrm{S}$ test) and particularly in D2 MSNs from R6/2 mice $(p<0.001$, $\mathrm{K}-\mathrm{S}$ test). In this and subsequent figures ${ }^{*} p<0.05,{ }^{* *} p<0.01$, and ${ }^{* * *} p<0.001$.

stimulation following standard procedures (Kita, 1993; Guzman et al., 2003; Tecuapetla et al., 2005). Electrical stimulation of the striatum 300-400 $\mu \mathrm{m}$ from the recorded cell with high $\mathrm{Cl}^{-}$internal solution, QX-314 in the pipette and in the presence of CNQX $(10 \mu \mathrm{M})$ and AP-5 $(50 \mu \mathrm{M})$ elicited inward currents at $-70 \mathrm{mV}$ (Fig. 3A). These currents were fully blocked by BIC (20 $\mu \mathrm{M}$ ) indicating that they were purely GABAergic (Fig. $3 A$ ). The input-output function at stimulation intensities between 0.002 and $0.012 \mathrm{~mA}$ evoked larger IPSC amplitudes in R6/2 (mean age $50 \pm 5 \mathrm{~d}, n=23$ ) compared with WT MSNs (mean age $55 \pm 3 \mathrm{~d}$, $n=15$ ). The difference in the input-output function reached 

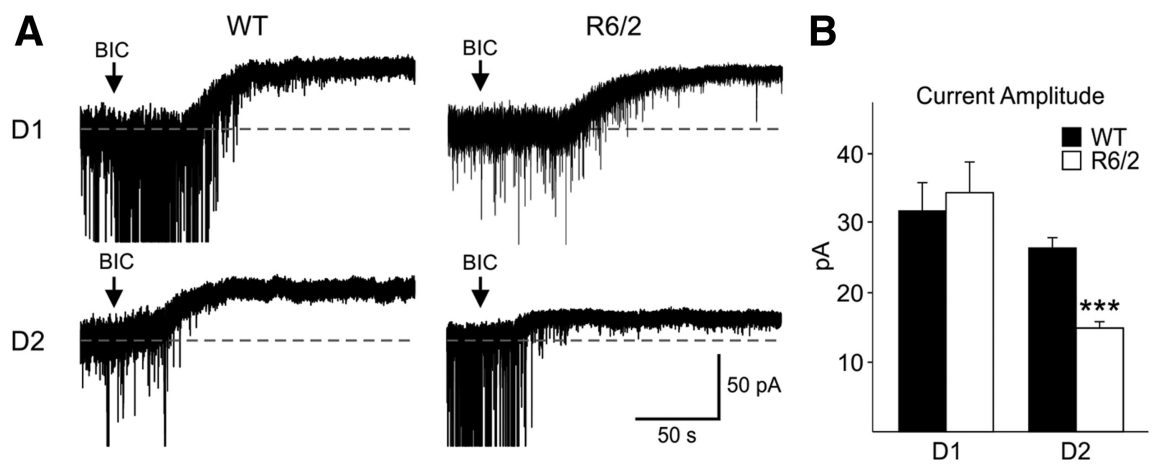

Figure 2. A, Examples of traces showing the amplitudes of tonic GABA currents in D1- and D2-expressing MSNs from WT and R6/2 mice. Recordings were in the presence of CNQX $(10 \mu \mathrm{M}), A P-5(50 \mu \mathrm{M})$, and CGP $(1 \mu \mathrm{M})$. The arrow in each trace represents the time when $\mathrm{BIC}(20 \mu \mathrm{M})$ was added. $\boldsymbol{B}$, Tonic GABA current amplitudes were significantly reduced only in D2 receptor-expressing MSNs from R6/2 mice.

A
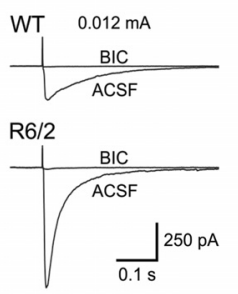

B
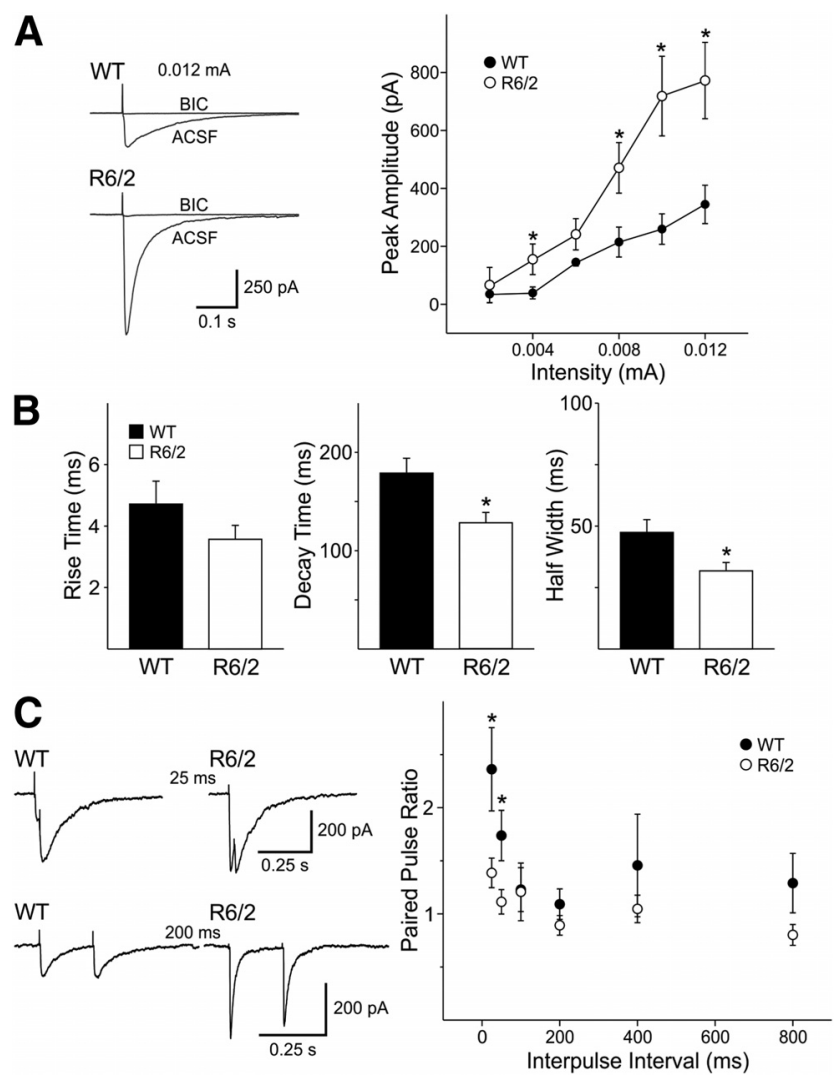

Figure 3. A, Examples of IPSCs from MSNs (CsCl internal solution containing $4 \mathrm{~mm}$ QX-314) evoked by intrastriatal stimulation in the presence of CNQX and AP-5. Stimulation evoked larger responses in $\mathrm{R} 6 / 2$ mice. These responses were completely blocked by BIC ( 20 $\mu \mathrm{M})$ demonstrating they were mediated by activation of $\mathrm{GABA}_{\mathrm{A}}$ receptors. Graph shows the input- output function between stimulus intensity and evoked peak IPSC amplitude in WT and R6/2 mice. At $0.004,0.008-0.012 \mathrm{~mA}$, responses were significantly larger in MSNs from R6/2 compared with WT MSNs. B, Kinetics of evoked GABAergic responses indicated that responses of MSNs from R6/2 mice had significantly faster decay times and half-widths. C, Typical PPRs at 25 and 200 ms interpulse intervals in MSNs from WT and R6/2 mice. Graph shows PPRs for intervals $25-800 \mathrm{~ms}$ in the two groups. Decreased paired-pulse facilitation in R6/2 MSNs, indicative of greater probability of neurotransmitter release, was significant at the 25 and 50 ms intervals.

statistical significance at stimulus intensities of $0.004,0.008$, 0.010 , and $0.012 \mathrm{~mA}$ (Fig. 3A, graph). In addition, the responses in MSNs from R6/2 mice demonstrated a trend for faster rise times, significantly shorter decay times $(p<0.05)$, and half- amplitude durations $(p<0.05)$ compared with those from WT MSNs (Fig. $3 B)$. Faster kinetics of evoked IPSCs in R6/2 mice could relate to different receptor subunit composition of $\mathrm{GABA}_{\mathrm{A}}$ receptors and/or alterations in GABA transporters.

To determine whether the larger IPSCs seen in R6/2 MSNs were due to changes in release probability, we compared PPRs. In WT MSNs, paired-pulse facilitation was seen at all, except $200 \mathrm{~ms}$, interpulse intervals. R6/2 MSNs displayed paired-pulse facilitation at 25, 50, and $100 \mathrm{~ms}$; no difference at $400 \mathrm{~ms}$; and paired-pulse depression at 200 and $800 \mathrm{~ms}$ (Fig. 3C). At 25 and $50 \mathrm{~ms}$, PPRs were significantly reduced in R6/2 MSNs compared with those from WTs $(p<0.05)$ indicating increased GABA release probability.

Feedback inhibition is reduced but bidirectional connectivity is increased in $\mathrm{R} 6 / 2$ mice

We hypothesized that the observed changes in inhibitory synaptic activity in MSNs from R6/2 mice were due to alterations in the feedback and/or feedforward GABAergic microcircuits. The feedback circuit consists of MSNs that interconnect with one another via local axon collaterals (Tepper et al., 2008). To determine whether feedback inhibition was altered in R6/2 mice, we recorded simultaneously from pairs of MSNs that were identified by their microscopic appearance as well as their passive and active membrane properties in currentclamp mode (Fig. 4A) (Koós et al., 2004). In connected neurons, action potential firing in the presynaptic neuron evoked depolarizing PSPs in the postsynaptic neuron (Fig. 4B,C). PSPs could be completely blocked by BIC $(20 \mu \mathrm{M})$ indicating they were GABAergic. Dual recordings were obtained from 66 WT and 67 R6/2 MSN pairs. In WT mice, $47 \%$ (or $23.5 \%$ if each pair is considered as two potential connections) of all recorded pairs were connected. In contrast, a significantly lower number of connected pairs were observed in R6/2 mice $(16 \%)\left(\chi^{2}\right.$ test, $\left.p<0.001\right)$ (Fig. $\left.4 D\right)$. The success rates, defined as the number of action potentials that evoked a response in the postsynaptic neuron converted to the percentage of the total number of action potentials tested, were not significantly different (19.4 \pm 0.96 in WT and $23.36 \pm 2.63$ in R6/2) (Fig. $4 E)$. Since glutamatergic and GABAergic changes in R6/2 mice are progressive and age dependent (Cepeda et al., 2003, 2004), we examined feedback inhibition in three age groups of R6/2 mice: $<30 \mathrm{~d}, 30-60 \mathrm{~d}$, and $>60 \mathrm{~d}$ group. There were significantly fewer connected MSN pairs in R6/2s in the three age groups (Fig. $4 F$ ). The success rates were not significantly different across the age groups (Fig. $4 G$ ). The mean PSP amplitude and area were significantly smaller in R6/2 compared with WT MSNs in the $>60 \mathrm{~d}$ group $(p<0.05$; Fig. $4 H, I)$. Mean PSP rise time also was significantly slower in R6/2 MSNs (Fig. $4 J$ ) while decay time was unchanged (Fig. $4 K$ ). In addition, we observed bidirectional (Fig. 4F, BD) connectivity between pairs of MSNs in R6/2 mice. In the 30-60 d and $>60 \mathrm{~d}$ age group $50 \%$ of all connected pairs were bidirectional (Fig. $4 F)$. In contrast, MSN-MSN connections in WTs were strictly unidirectional. 
A

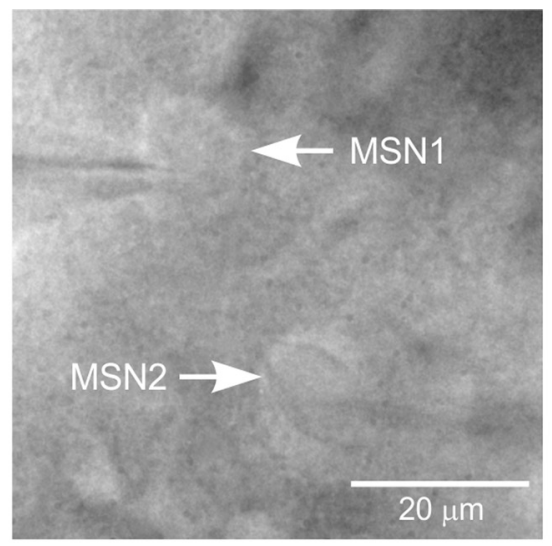

B
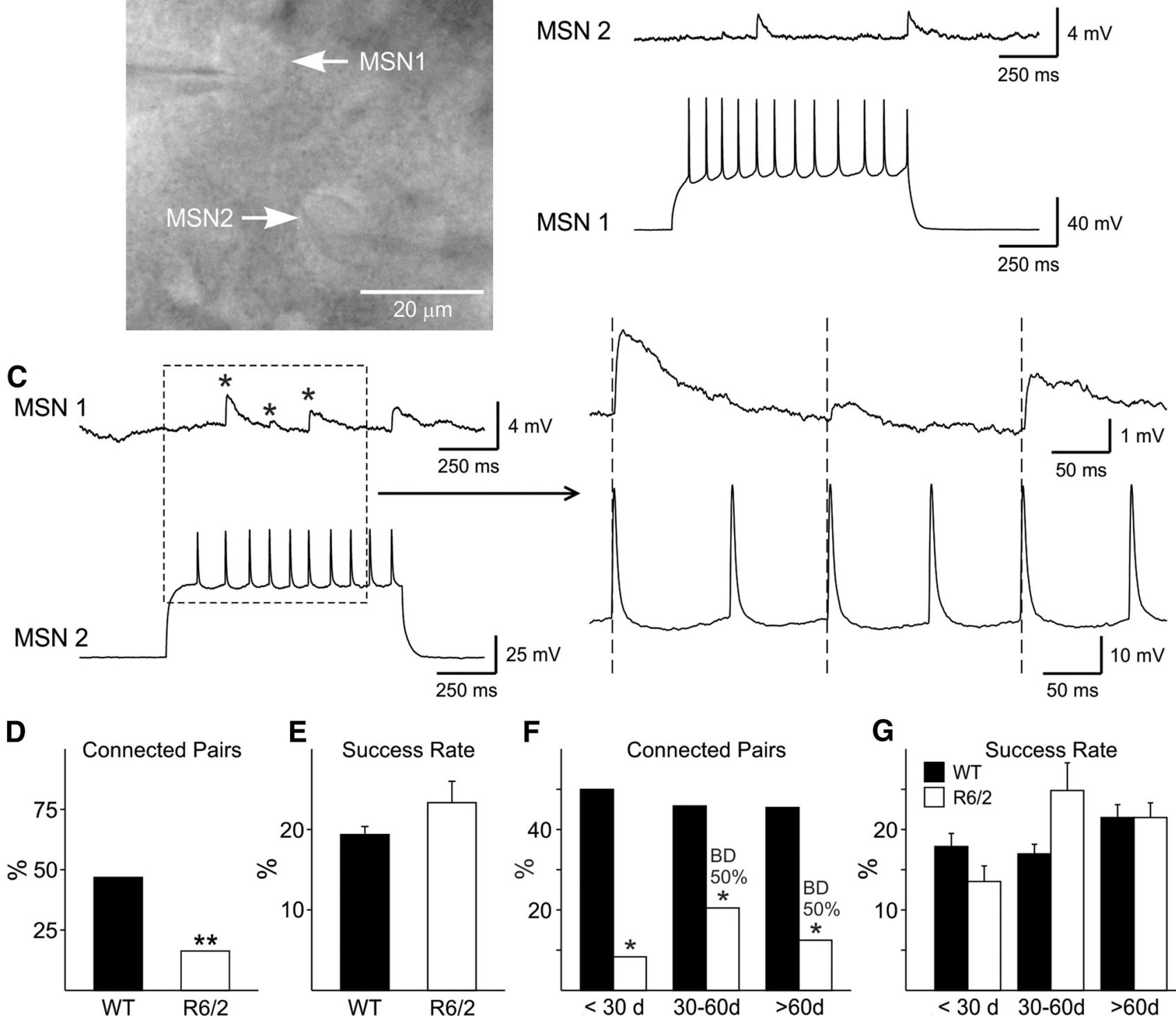

E

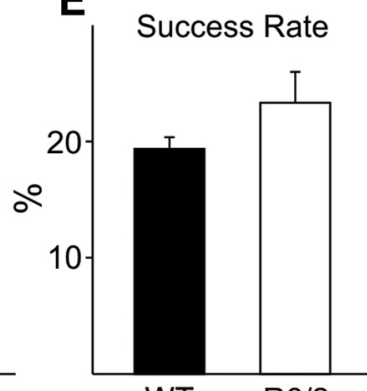

H

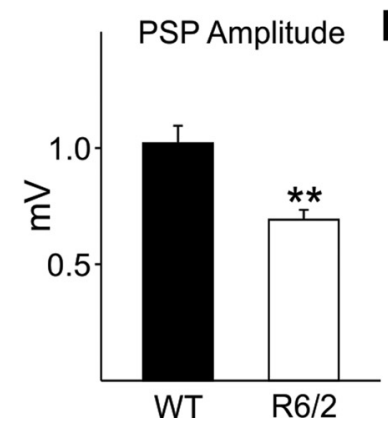

F

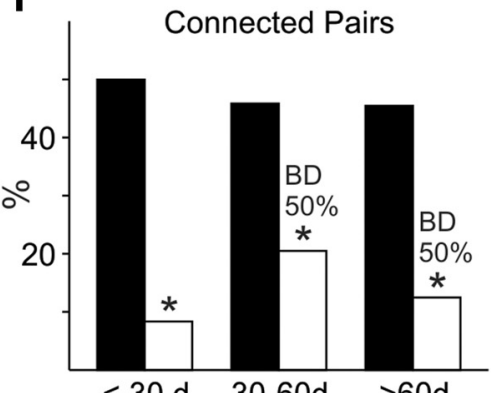

$<30$ d $30-60 d \quad>60 d$

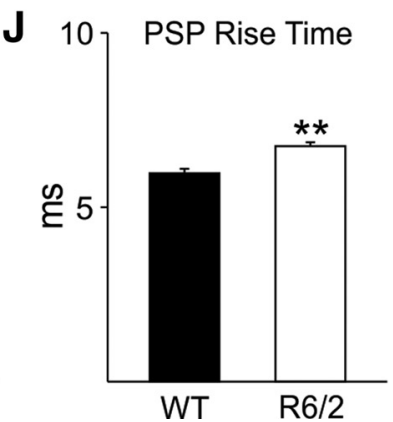

G
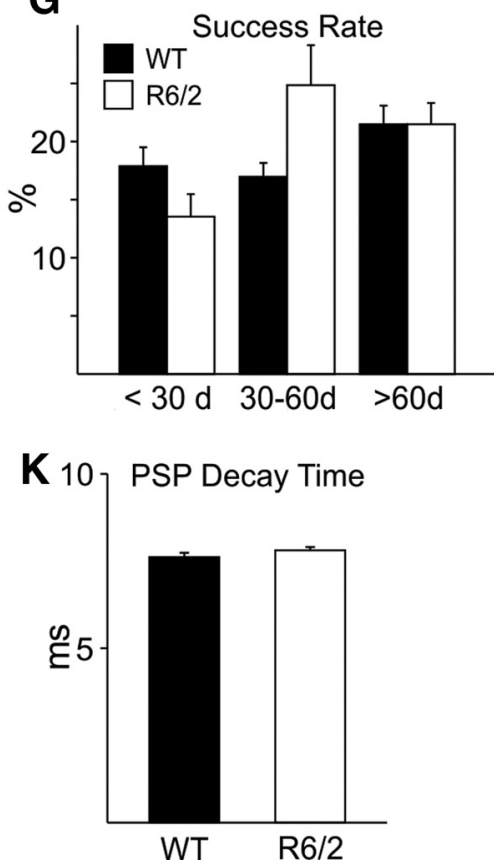

Figure 4. $\quad \boldsymbol{A}, \mathrm{IR}-\mathrm{DIC}$ image of two MSNs (from an R6/2 mouse) that were bidirectionally connected. $\boldsymbol{B}$, Depolarization-induced action potentials in MSN 1 evoked time-locked PSPs in MSN 2. C, Depolarizationinduced action potentials in MSN 2 evoked PSPs in MSN 1. Traces on the right are the enlarged area in the dashed box. Asterisks show the three evoked PSPs. $\boldsymbol{D}$, There was a reduced proportion of connected pairs in R6/2 MSNs compared with WTs (31/66 vs 11/67 in WT vs R6/2; $\chi^{2}$ test, $p<0.001$ ). E, Success rates, although slightly increased in R6/2 MSNs compared with those from WTs, were not significantly different. $\boldsymbol{F}$, At each age there was a significant decrease in the proportion of connected pairs in MSNs from R6/2s compared with WTs. BD indicates that bidirectional connected pairs were present $50 \%$ of the time in MSNs, but only in R6/2 mice. G, Success rates were similar in MSNs from WT and R6/2 mice at the $<30$ and $>60$ d groups but were increased in MSNs from R6/2 mice between 30 and $60 \mathrm{~d}$. These differences were not statistically significant. $\boldsymbol{H}-\boldsymbol{K}$, The PSP amplitudes and areas were significantly smaller in MSNs from R6/2 mice. PSP rise time was significantly slower and decay times were similar.

D1-D1 MSN connectivity is increased in R6/2 mice

In mice expressing EGFP in D1 or D2 MSNs, dual recordings were obtained in WT $(n=24$ pairs, age $45 \pm 4 \mathrm{~d})$ and R6/2 mice $(n=24$ pairs, age $50 \pm 5 \mathrm{~d}$ ) (Fig. $5 A, B)$. In WT mice, unidirec- tional synaptic connections were seen in $41.6 \%$ (10 of 24) of all recorded pairs. Of the $10 \mathrm{WT}$ connected pairs, $40 \%$ ( 4 of 10 ) were D1-D1 and 20\% (2 of 10) were D2-D2 connections (Fig. 5C). Mixed D1-D2 pairs were connected 40\% (4 of 10) of the time, 


\section{A}
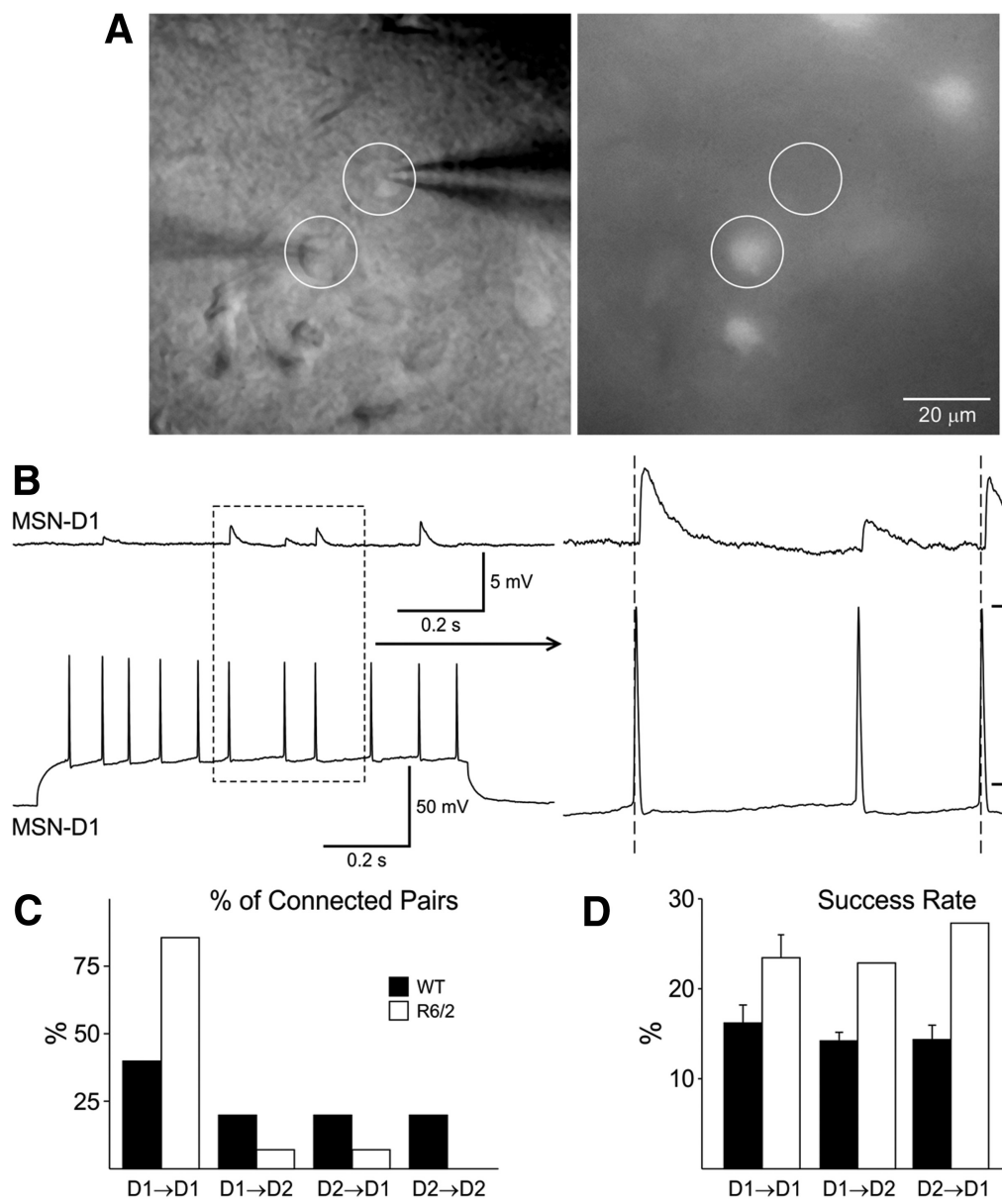

D

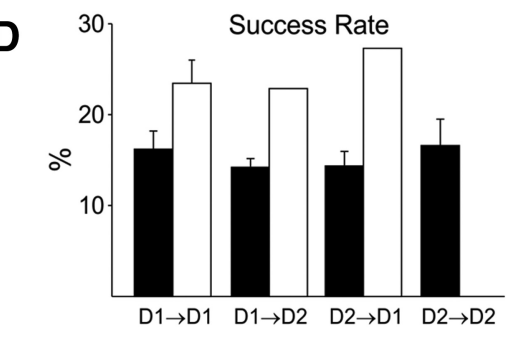

Figure 5. A, Example of a D1-D2 connected pair from a WT mouse. Left, IR-DIC image. Right, Fluorescent image. Only the circled cell on the bottom displays fluorescence. $\boldsymbol{B}$, Example of a connection between two D1-MSNs from an R6/2 mouse. Traces on the right are the enlarged area in the box. C, In MSN connected pairs (10/24) from WT mice, only unidirectional connectivity occurred. Forty percent (4/10) were D1-D1 and 20\% (2/10) were D2-D2 connections. Mixed D1-D2 pairs were connected 40\% (4/10) of the time. In MSN connected pairs (7/24) from R6/2 mice, two displayed bidirectional connectivity (counted as two connections, D1 to D1, D1 to D2). The great proportion of connected pairs was between D1-D1 MSNs (6/7). No connected D2-D2 pairs were observed. There also were fewer connected mixed pairs in R6/2 mice when compared with WTs. D, Success rates for D1-D1 connections were slightly higher for R6/2 than WT MSNs. The success rates for R6/2 pairs for D1-D2 and D2-D1 connections were based on one pair in each group and there was no SE.

with the D1-MSN being presynaptic in half and D2-MSN being presynaptic in the other half. The mean success rates of the identified connected pairs were not significantly different across the groups ( $p=0.683$; ANOVA) (Fig. $5 D$ ).

In R6/2 mice, synaptic connections were detected in $29.1 \%$ (7 of 24) of all recorded pairs with two pairs being reciprocally connected. Six of the seven connected pairs were between D1-D1 MSNs and one D1-D1 pair was bidirectionally connected. The other connected pair was a D1-D2 pair that also was bidirectionally connected. Overall, there was more D1 interconnectivity in the R6/2 although success rates were not significantly different. In contrast, no D2-D2 pairs were connected in R6/2 mice while $28.5 \%$ of D2-D2 pairs were connected in WT. Also, there were fewer connected mixed pairs in R6/2 mice when compared with $\mathrm{WT}$. In conclusion, in R6/2 mice the greater proportion of connections involved D1-D1 pairs while in WT mice connections between D1-MSNs and D2-MSNs and between D1-D1 and D2-D2 MSNs were more evenly distributed.

\section{Feedforward inhibition is increased in R6/2 mice}

The striatal feedforward circuit consists of GABAergic interneurons that receive excitatory input from the cortex and thalamus and inhibit MSNs. We recorded from pairs of GABAergic interneurons and MSNs to examine feedforward inhibition. FS interneurons were identified by a combination of Lhx6-EGFP expression and/or electrophysiologically by their sustained high-frequency firing in response to suprathreshold depolarizing currents and the large amplitude action potential afterhyperpolarization (Kawaguchi et al., 1995; Tepper and Bolam, 2004; Kreitzer, 2009). No significant differences in passive membrane properties between FS interneurons from WT and R6/2 mice were found (Table 1).

Consistent with previous reports (Koós and Tepper, 1999) FS-MSN connectivity and success rate were significantly higher than those in MSN-MSN pairs and trains of action potentials caused summation of responses and compound PSPs in MSNs connected to FS interneurons (Fig. 6A). Dual recordings from FS-MSN pairs in WT (9 pairs) and R6/2 (9 pairs) mice were obtained and the injected current was adjusted to induce $15-20 \mathrm{~Hz}$ firing in the interneuron. The number of connected pairs was slightly higher in R6/2 (6/9, 67\%) compared with WT $(5 / 9,56 \%)$ mice. Success rates also were slightly higher but the difference was not statistically significant $(49.95 \pm 10.6$ in WT vs $58.4 \pm 9.4$ in R6/2) (Fig. 6B). There was a trend for the average amplitude of evoked PSPs from MSNs in R6/2 mice to be higher than that from MSNs of WTs $(1.4 \pm 0.4$ in WT vs $6.0 \pm 2.5 \mathrm{mV}$ in $\mathrm{R} 6 / 2$ ), but responses in the R6/2 were variable in amplitude. No differences in kinetics were found (data not shown).

We then examined whether feedforward inhibition from one other principal type of GABAergic interneuron in the striatum, the PLTS interneuron, was altered in R6/2 mice (Fig. 6C). PLTS interneurons were identified by a combination of Lhx6-EGFP expression and/or electrophysiologically by their high input resistance, depolarized RMP, and time-dependent "sag" upon hyperpolarization, as well as the presence of plateau depolarizations and rebound excitation (Tepper et al., 2010) (Fig. 7A). The vast majority of these cells fired spontaneously. At high intensity current pulses, these cells generally displayed adaptation of action potentials. The mean cell membrane capacitance, input resistance, and time constant in WT and R6/2 PLTS interneurons were not significantly different (Table 1). In addition, there were no significant differences in RMPs $(-55.7 \pm 1.9 \mathrm{mV}$ in WT and $-58.1 \pm 1.6$ in R6/2) between neurons in the two groups.

Dual recordings from PLTS-MSN pairs in WT (19 pairs) and R6/2 mice (21pairs) showed no significant difference in the connectivity or success rates (WT: $10.5 \%$ connectivity, success rate $25.37 \pm 4.5 ; \mathrm{R} 6 / 2: 14.3 \%$ connectivity, success rate $14.4 \pm 3.2$ ) (Fig. 6D). Because of the low intrinsic connectivity between PLTS-MSN pairs (only $2-3$ per group), meaningful conclusions about response amplitudes and kinetics cannot be drawn. 
In current-clamp, we also assessed spontaneous firing of PLTS interneurons from WT and R6/2 mice. If the interneuron fired more than two action potentials in a 2 min observation period in the absence of any applied stimuli, it was considered to be spontaneously active. Figure $7 B$ shows examples of spontaneous firing recorded from WT and R6/2 PLTS interneurons. There was a significantly higher frequency of spontaneous action potentials in interneurons from $\mathrm{R} 6 / 2$ compared with WT mice $(0.68 \pm 0.2 \mathrm{~Hz}$, $n=15$ in WT; $1.6 \pm 0.3 \mathrm{~Hz}, n=15$ in $\mathrm{R} 6 / 2, p<0.02)$ and the PLTS neurons tended to fire in bursts (Fig. $7 B$ ). The rheobase was calculated in a subset of PLTS neurons with infrequent action potentials at rest or by injecting negative current to set the membrane at a predetermined RMP $(-80 \mathrm{mV})$. No significant differences were found $[43.4 \pm 4.5$ vs $40 \pm 5.7 \mathrm{pA}$ at RMP and $182 \pm 7.5 \mathrm{vs}$ $171.2 \pm 15.4$ at $-80 \mathrm{mV}$ in cells from WT $(n=9)$ and R6/2 $(n=18)$ mice, respectively]. The higher firing rate observed in PLTS interneurons in R6/2 mice suggest that, although sparsely connected, there is increased feedforward inhibition from PLTS interneurons in R6/2 mice.

\section{Optogenetic stimulation of FS and PLTS striatal interneurons}

To further identify the source of increased GABA synaptic activity on MSNs, we used optogenetic methods to selectively stimulate FS or PLTS interneurons. PV-positive staining colocalized with EYFP-positive cells demonstrating the construct was only expressed in this class of interneurons (Fig. $8 A$ ). Whole-cell patch-clamp recordings from PV interneurons and MSNs were obtained using Cs-methanesulfonate as the internal patch pipette solution. Blue light stimulation induced inward currents in PVpositive interneurons confirming they were excited by light (Fig. 8B). In MSNs held at $+10 \mathrm{mV}$, blue light stimulation evoked outward currents that were completely blocked with BIC and were not evoked by yellow light stimulation (Fig. 8C). GABA currents induced by light stimulation of striatal PV interneurons were significantly larger $(p<0.03, n=17 \mathrm{WT}$ and $n=29 \mathrm{R} 6 / 2)$ in MSNs from R6/2 compared with WT mice (Fig. 8C,D). In addition, the kinetics of light-evoked responses were significantly faster in MSNs from R6/2 compared with WT mice ( $p<0.006$; Fig. $8 D$ ), similar to changes observed using electrical stimulation.

When SOM interneurons were stimulated, there were no significant differences in response amplitude between MSNs recorded from WT and R6/2 mice (Fig. 9C, left graph). However, the rise and decay times of MSN responses were significantly faster in R6/2 than WT mice ( $p<0.05$ for rise time and $p<0.05$ for decay time, $n=22$ WT and $n=27$ R6/2) (Fig. $9 C$, middle and right graphs).
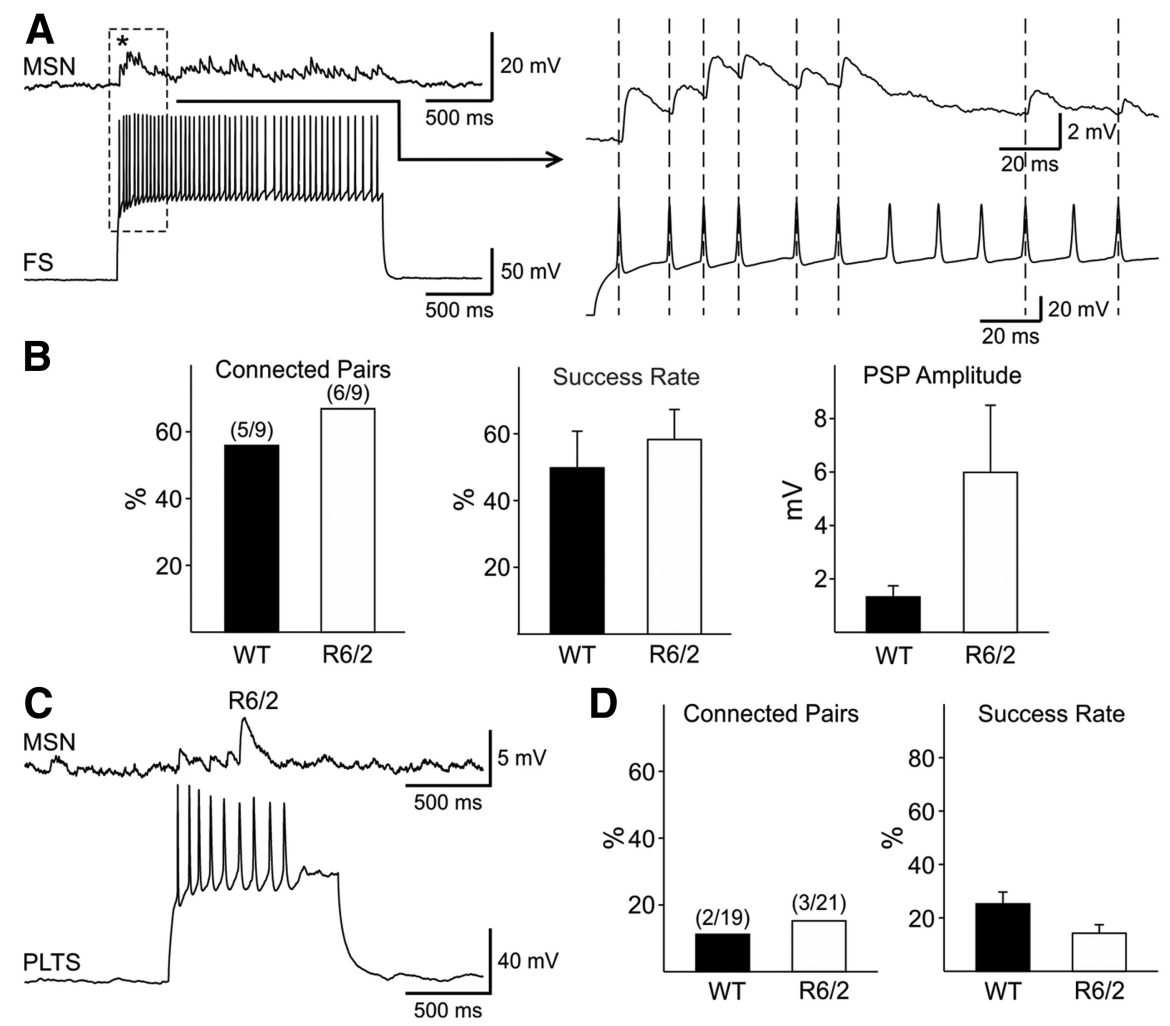

Figure 6. $A$, Example of depolarization evoked action potentials in an FS interneuron inducing PSPs in an MSN. The enlargement of the dashed box on the right shows summation of PSPs in the MSN. B, FS-to-MSN connectivity was slightly increased in pairs from R6/2 compared with WT mice. Middle and right graphs show that there was no significant difference in the success rates between pairs from WT and R6/2 mice, but there was a trend for PSP amplitudes to be larger and more variable in MSNs from R6/2 mice. $C$ The traces show dual recordings between a PLTS-MSN pair in an R6/2 mouse. $\boldsymbol{D}$, There were no significant differences in the connectivity or success rate between PLTS-MSN pairs from WT and R6/2 mice.
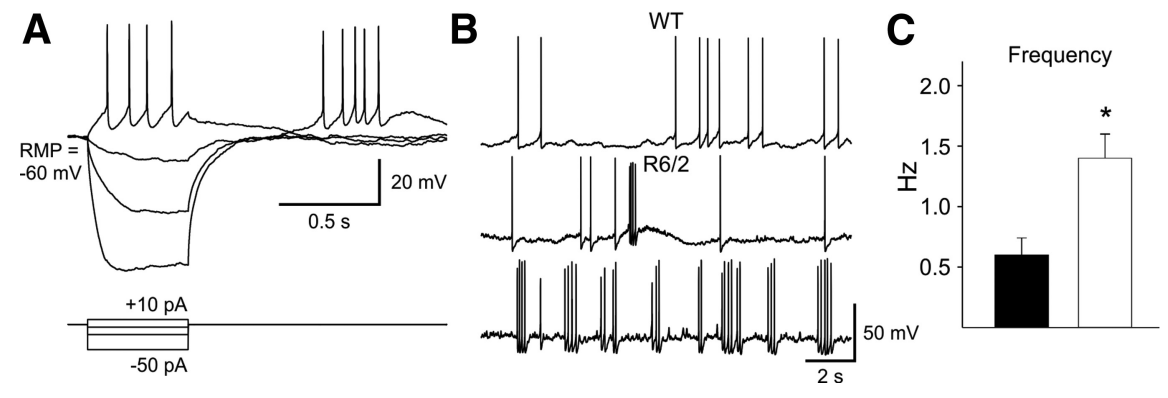

Figure 7. A, Traces showing a PLTS interneuron from a WT mouse identified electrophysiologically by a depolarized RMP and time-dependent "sag" upon hyperpolarization, as well as the presence of plateau depolarizations and rebound excitation. $\boldsymbol{B}$, Traces of spontaneous action potentials recorded in current-clamp mode from WT and R6/2 PLTS interneurons. Note the increased spontaneous firing and bursting in the PLTS neurons from R6/2 mice. C, Bar graph shows that there was a significantly higher frequency of spontaneous firing in PLTS interneurons from R6/2 compared with WT mice.

MSN current responses induced by light stimulation of SOMexpressing interneurons were significantly smaller than those induced by stimulation of PV-expressing interneurons in both WT (176 \pm 25 vs $447 \pm 48 \mathrm{pA}$ for SOM vs PV interneuron stimulation, $p<0.001)$ and $\mathrm{R} 6 / 2$ mice (144 \pm 18 vs $692 \pm 78 \mathrm{pA}$ for SOM vs PV interneuron stimulation, $p<0.001$ ) indicating reduced connectivity and synaptic strength of putative PLTS-MSN connections compared with FS-MSN connections, thus confirming results obtained with dual patch recordings.

Viral infection efficiency and differential construct expression may have affected the outcomes especially relating to amplitude differences of IPSCs evoked in MSNs using optogenetics. For 

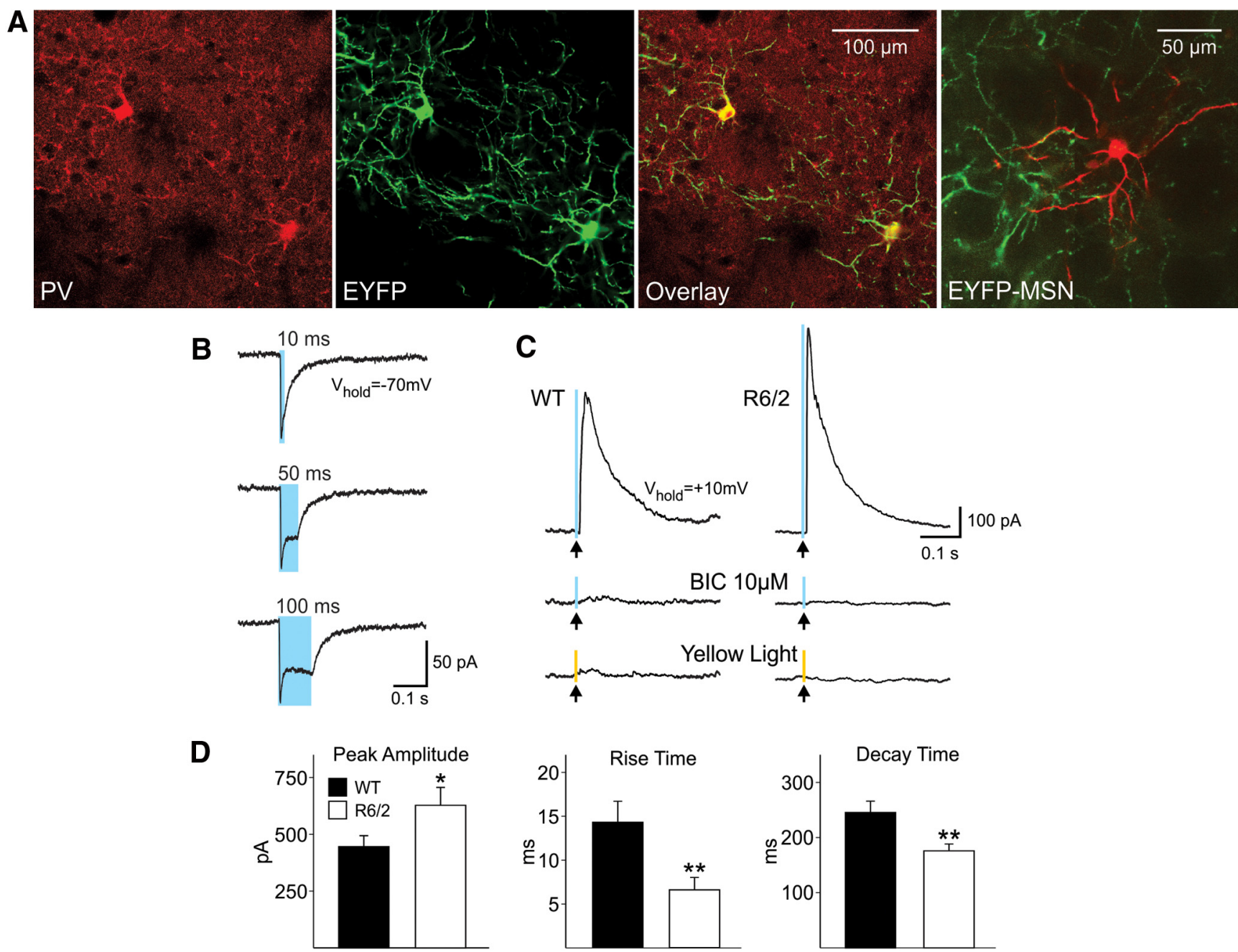

Figure 8. A, The expression of PV was visualized by colocalization of immunostaining for PV (red) and expression of EYFP fluorescence of ChR2-PV (green) to demonstrate the construct was only expressed in PV interneurons (yellow). The last panel shows a biocytin-filled MSN (red) surrounded by EYFP expression (green) in axons from PV interneurons. $\boldsymbol{B}$, Inward currents evoked by blue light $(0.5 \mathrm{~ms}$ duration, $8 \mathrm{~mW}$ power) in a PV-positive interneuron. Note that increasing the duration of the light increases the duration of the current. C, Outward currents evoked from MSNs in WT and R6/2 mice in response to blue light stimulation $(0.5 \mathrm{~ms}$ duration, $8 \mathrm{~mW}$ power) at a holding potential of $+10 \mathrm{mV}$. These currents were blocked by BIC ( $10 \mu \mathrm{M})$ and were not evoked by yellow light (0.5 ms duration light pulse, $2 \mathrm{~mW})$. D, Bar graphs show significantly increased mean peak amplitude $(p<0.05)$ and faster rise $(p<0.01)$ and decay times $(p<0.01)$ in MSNs from R6/2 compared with those from WT mice.

example, levels of expression may be different in WT and R6/2 mice. However, there are findings that argue against simple differential expression. Since the optogenetic responses of R6/2 MSNs were larger to activation of PV interneurons, it seems counterintuitive to argue for a decrease in expression of the viral construct in the R6/2. Also, since different results from activation of PV (a significant increase) and SOM (a trend toward a decrease) interneurons were obtained with optogenetics in the R6/2, one would have to argue for differential efficiency of expression patterns for each construct. Thus, this differential effect serves as a reasonable internal control. However, to be more certain, the number of PV and SOM interneurons expressing the fluorescent reporter was counted in slices used for electrophysiology and in a few mice not used for electrophysiology. There were no significant differences between WT and R6/2 mice for counts of PV- or SOM-expressing neurons. For PV-expressing interneurons, the numbers were $6.81 \pm 1.57$ and $7.43 \pm 1.30$ cells $/ \mathrm{mm}^{2}$ from WT $(n=4)$ and $\mathrm{R} 6 / 2(n=4)$ mice, respectively, and for SOM-expressing interneurons the numbers were $7.16 \pm 0.81$ and $7.05 \pm 0.57$ cells $/ \mathrm{mm}^{2}$ from WT $(n=2)$ and $\mathrm{R} 6 / 2(n=2)$ mice, respectively.

\section{Alterations in MSNs and GABAergic interneurons in BACHD mice}

To determine whether some of the findings in R6/2 mice could be extended to other HD models, we recorded MSNs and interneurons from the full-length BACHD mouse model at two ages (2 months, presymptomatic and 12 months, symptomatic) (Gray et al., 2008). We replicated the observation of increased GABA synaptic activity in BACHD mice (aged 12 months). This increase, similar to R6/2 mice, was evident in indirect pathway MSNs and less so in direct pathway MSNs (Fig. 10).

WT and BACHD mice expressing Lhx6-EGFP also were used to identify and record from interneurons in the striatum. FS and PLTS interneurons were distinguished using their electrophysiological signatures (Tepper et al., 2010). Of all EGFP-positive neurons that were recorded, $43 \%$ were FS and 57\% were PLTS interneurons in WT mice. Similarly, in BACHD mice $40 \%$ of EGFP-positive neurons were FS and 60\% were PLTS interneurons. While there were expected differences in passive membrane properties between FS and PLTS interneurons, there were no 
significant differences between WT and BACHD mice in either interneuron type at both ages examined (Table 1).

Spontaneous action potential firing in both types of interneurons was assessed in the cell-attached mode. FS interneurons did not fire spontaneously in slices from WT or BACHD mice. In contrast, PLTS interneurons from BACHD mice displayed significantly higher firing rates when compared with those from WTs at both 2 and 12 months $(p<0.05 t$ test at 2 months; Mann-Whitney $U$ test at 12 months) (Fig. 11A), similar to findings in R6/2 mice. As firing frequency in GABAergic interneurons can be modulated by synaptic inputs, we also examined sIPSCs in PLTS interneurons in the presence of glutamate receptor antagonists CNQX and AP-5. In cells from both age groups, a significant reduction in mean frequency of total IPSCs was observed in BACHD $(n=7)$ compared with WT $(n=8)$. In contrast, there was no difference in mean IPSC amplitudes (Fig. 11B). In the presence of TTX, PLTS interneurons showed no difference in frequency at 12 months $(0.26 \pm 0.06 \mathrm{~Hz}, n=3$ in WT and $0.1 \pm 0.02 \mathrm{~Hz}, n=2$ in $\mathrm{BACHD})$. Thus, PLTS interneurons from BACHD mice receive reduced activity-dependent inhibitory inputs and fire more action potentials than WT neurons. In contrast, there was a significant increase in the mean frequency of sIPSCs in FS interneurons in BACHD mice when compared with WT at both 2 and 12 months (Fig. $11 C$, inset). The sIPSC amplitudes also were not significantly different (Fig. 11C). This suggests increased inhibitory input to FS interneurons and potentially reduced firing in BACHD mice. The frequency of spontaneous EPSCs was very low and not significantly different between WT and BACHD mice in either FS or PLTS interneurons at both ages (FS, $0.5 \pm 0.2, n=5$ and $0.2 \pm 0.1 \mathrm{~Hz}, n=5$ and $0.4 \pm 0.2, n=3$ and $0.2 \pm 0.1 \mathrm{~Hz}, n=$ 3 in WT and BACHD at 2 and 12 months, respectively; PLTS $0.4 \pm 0.2, n=7$ and $0.5 \pm 0.1 \mathrm{~Hz}, n=7$ and $0.5 \pm 0.1, n=4$ and $0.6 \pm 0.1 \mathrm{~Hz}, n=3$ in WT and BACHD at 2 and 12 months, respectively).

\section{Discussion}

The present study was designed to uncover the possible sources of increased GABA synaptic activity in HD mouse models. Single patch recordings demonstrated an increase in sIPSC frequency in MSNs from symptomatic HD mice and this effect occurred primarily in indirect pathway MSNs, confirming observations in symptomatic YAC128 HD mice (André et al., 2011b). We also demonstrate that evoked IPSCs are increased in amplitude in $\mathrm{R} 6 / 2$ mice and that this increase is likely presynaptic based on PPRs. Paradoxically, while spontaneous and evoked GABA currents are increased, tonic currents are reduced in HD mice but only in MSNs of the indirect pathway. Dual patch recordings revealed that there is a significant decrease in synaptic connectivity between pairs of MSNs in R6/2 mice compared with WT littermates across age. However, in contrast to WT MSNs where bidirectional connectivity was not observed, about half of the connected pairs in symptomatic R6/2 mice showed bidirectional connectivity, suggesting altered axon collateral inhibition.
Whether bidirectional connectivity contributes significantly to increased GABA activity remains unclear. Since MSNs are more depolarized in symptomatic R6/2 mice (Klapstein et al., 2001), they may produce more spontaneous action potentials not only in vivo (Rebec et al., 2006) but also in vitro, thus providing a possible source of increased GABAergic inputs in HD. Indeed, a recent study suggested that increased GABA activity could be the result of disinhibition of spontaneous action potential generation (Dvorzhak et al., 2013). However, considering that MSN connectivity is decreased in HD, the role of the MSNs as a source of increased GABA activity is probably minor.

In dorsal and ventral striatum reciprocal MSN connectivity is a rare finding (Tunstall et al., 2002; Koós et al., 2004; Taverna et al., 2004). Using EGFP as a reporter gene for MSNs of the direct and indirect pathways, one study found that recurrent collaterals are not randomly distributed. Thus, D1 cells form functional connections primarily with other D1 cells, whereas D2 MSNs form recurrent connections with both D2 and D1 MSNs. In addition, synapses formed by D1 MSNs appear to have significantly smaller numbers of $\mathrm{GABA}_{\mathrm{A}}$ receptors than those formed by $\mathrm{D} 2$ MSNs (Taverna et al., 2008). Interestingly, disruption of collateral connectivity was observed in models of Parkinson's disease (Taverna et al., 2008). While in HD models we also found disrupted connectivity, the fact that bilateral connectivity between D1 MSNs was increased could be a marker of HD abnormalities that could translate into reduced output in this population and contribute to bradykinesia in HD mice.

The reduction of tonic $\mathrm{GABA}_{\mathrm{A}}$ currents in parallel with increases in synaptic currents is intriguing. If tonic GABA is neuroprotective, as was recently proposed (Santhakumar et al., 2010), reduced tonic GABA activity, particularly in indirect pathway neurons, may contribute to their increased susceptibility in HD. Decreased tonic GABA currents could be the result of reduced density and/or sensitivity of $\mathrm{GABA}_{\mathrm{A}}$ receptors expressing the $\delta$-subunit or changes in GABA transporters (Brickley and Mody, 2012). A recent study in the N171-82Q mouse model 

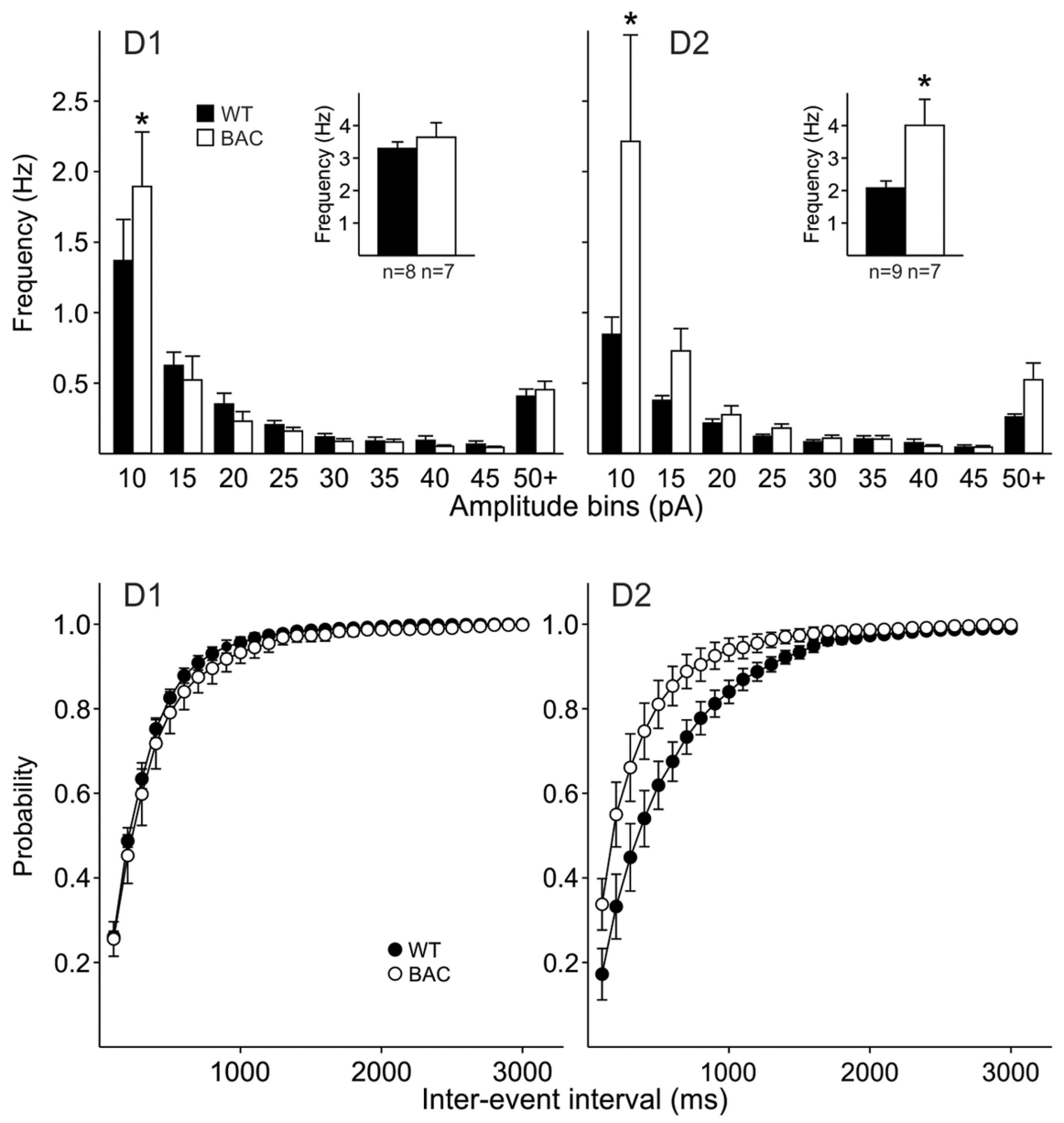

Figure 10. Amplitude-frequency histograms of sIPSCs in MSNs from 12 month BACHD and WT mice indicate that D1-MSNs did not show significantly different frequencies of events compared with WTs (top, left). Inset shows mean frequencies. In contrast, D2-MSNs in BACHD mice showed a significant increase in the frequency of SIPSC sin the 5-10 pA bin and the mean frequencies were significantly increased (inset) (top, right). Bottom graphs show the cumulative interevent interval probability distributions. There were no differences in the interevent interval histograms for the D1 receptor-expressing MSNs. There was a significant difference in the interevent interval histograms from D2 MSNs from BACHD mice ( $p<0.05, \mathrm{~K}-\mathrm{S}$ test).

demonstrated deficits in postsynaptic cortical and striatal GABA responses caused by impaired $\mathrm{GABA}_{\mathrm{A}}$ receptor trafficking due to disruption of the complex formed by huntingtin associated protein 1 and the kinesin family motor protein 5 (Yuen et al., 2012).

When FS and PLTS interneuron-MSN pairs were examined, we found a small increase in FS-MSN connectivity in R6/2 mice. Using optogenetic techniques to selectively stimulate this type of interneuron we showed significantly increased response amplitudes in MSNs from R6/2 mice, pointing to another source of increased GABA inputs. However, FS interneurons generally do not fire spontaneously, at least in slices. Single patch recordings from PLTS interneurons demonstrated increased firing in R6/2 and BACHD mice. Dual patch recordings indicated similar connectivity and optogenetic stimulation of SOM interneurons did not yield increased response amplitudes in MSNs. It is possible that sampling of different subpopulations of PLTS interneurons (Tepper et al., 2010), expressing different markers, could explain some of these differences.

Dual patch recordings of the two main classes of striatal inhibitory interneurons and MSNs as well as the optogenetics demonstrated higher connectivity in FS-MSN pairs compared with PLTS-MSN pairs. In fact the latter connection is so rare that it is considered by some to be almost nonexistent (Gittis et al., 2010).
In our hands, only $\sim 10 \%$ of pairs appeared connected. Using optogenetics we demonstrated that there is connectivity, although it does not appear to be markedly different in WT and R6/2 mice. The increased firing indicates a role of PLTS interneurons in HD. For example, PLTS interneurons can release NO, NPY, and SOM, which can have neuroprotective effects (Bazzett et al., 1997; Deckel, 2001; Galarraga et al., 2007). Thus, increased firing of PLTS interneurons in HD could represent a physiological compensatory and protective mechanism.

For interneuron connectivity to MSNs there are a number of similarities among the findings with paired recordings and optogenetics. There is a trend for synaptic responses to be larger in MSNs from R6/2 mice in the paired FS-MSN recordings and these responses are more variable in size in the R6/2 as well. With optogenetics there was a significant increase in the size of the response in the R6/2 MSNs when PV neurons were activated and there appeared to be two populations of responses, one larger in amplitude than WTs and one about the same size demonstrating increased variability. For PLTS neurons there also were similarities. With dual recordings there was no change in connectivity between WT and R6/2 MSNs. However, responses after SOM/ PLTS interneuron optogenetic stimulation resulted in reliable evoked responses in MSNs, which could mean that synchronous activation of multiple SOM interneurons is necessary to achieve significant responses due to the weakness of their individual connectivity. Interestingly, when response amplitudes of MSNs to activation of PV or SOM interneurons were compared using optogenetics in both WTs and R6/2s, responses to PV activation were much larger than responses to SOM activation consistent with stronger connectivity and reliability of FS-MSN connections, which was demonstrated by dual patch recordings.

An intriguing observation was the increased number of PLTS interneurons that fire in bursts. Interestingly, after dopamine depletion, PLTS interneurons also discharge in bursts (Dehorter et al., 2009). In symptomatic HD mice, dopamine release is significantly reduced (Johnson et al., 2006). Thus, it is likely that a similar process underlies bursting activity in PLTS interneurons. A recent study also indicated an age-dependent increase in burst rates of substantia nigra pars reticulata neurons from knock-in HD but not WT mice (Murphy-Nakhnikian et al., 2012).

In striatal slices, the majority of PLTS interneurons in striatum fire spontaneously due to a relatively depolarized RMP (Tepper et al., 2010). As we previously demonstrated that increased GABA synaptic events is activity dependent (Cepeda et al., 2004), spontaneously firing PLTS interneurons likely contribute to this effect. While the exact mechanism remains unknown, it is possible that increased firing could be the consequence of a gain of 
A

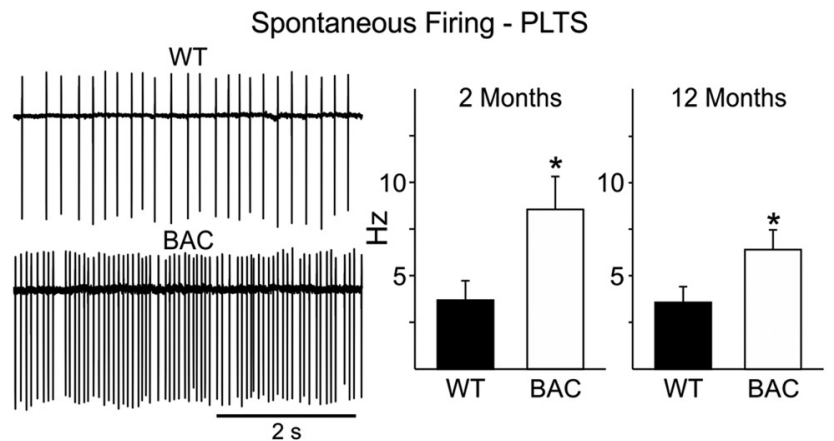

B

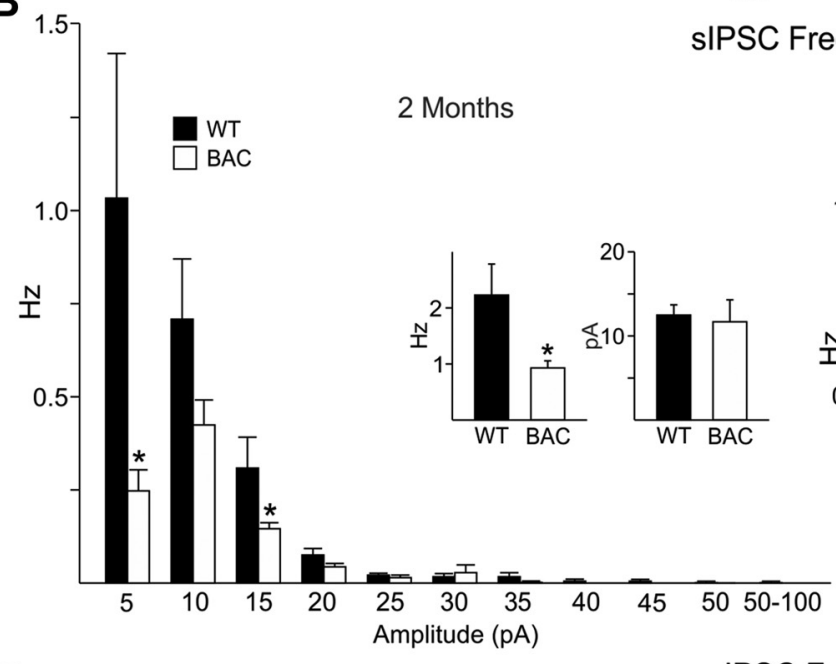

requency - PLTS
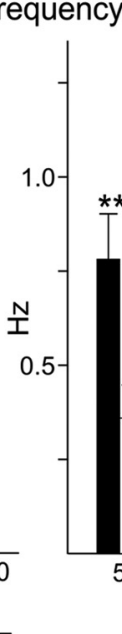

12 Months

C
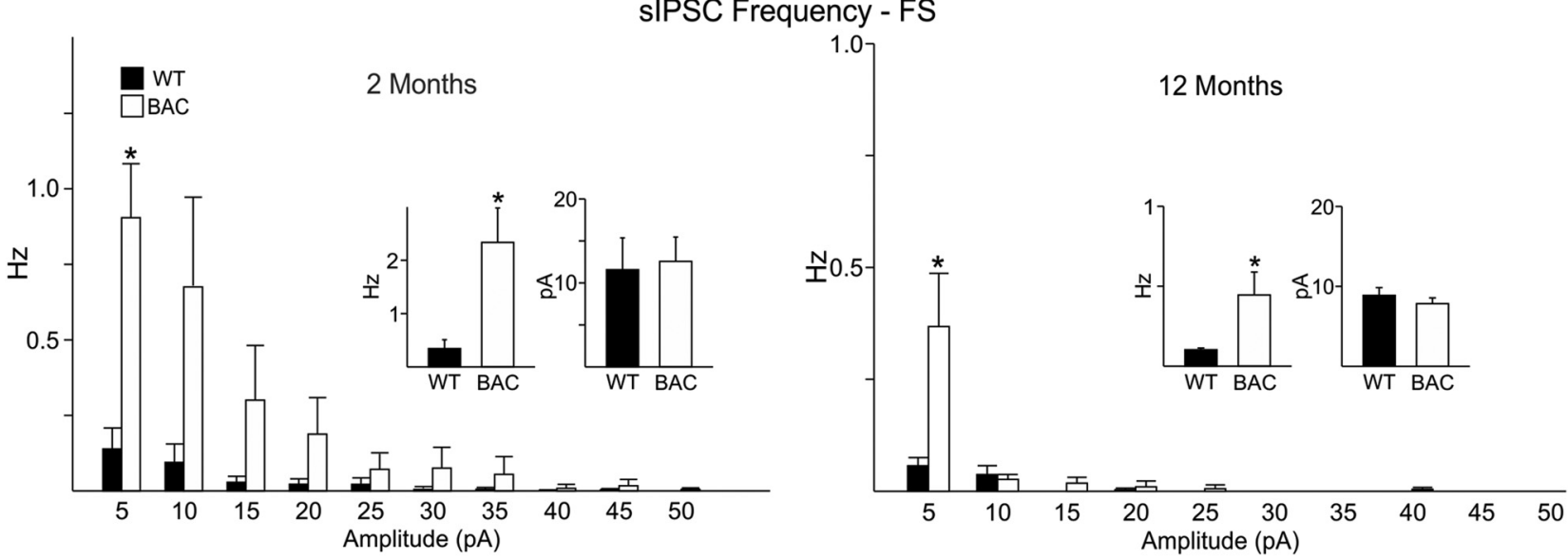

Figure 11. A, Traces showing spontaneous firing in the cell-attached mode from WT and BACHD PLTS cells from the 2 month age group. Right bar graphs show that spontaneous action potential firing in PLTS interneurons from BACHD mice was significantly increased when compared with those of WTs at both ages ( $p<0.05, t$ test for comparisons at 2 months, Mann-Whitney $U$ test for comparison at 12 months). $\boldsymbol{B}$, Amplitude-frequency histograms of IIPS (s from PLTS interneurons from WT and BACHD mice at 2 and 12 months (insets are averages). There was a significant reduction in mean frequency of sIPSCS in BACHD PLTS neurons, mainly in the small amplitude events, compared with those of WTs at both 2 and 12 months but no difference in mean sIPSC amplitudes. C, Amplitude-frequency histograms of sIPSCs from FS interneurons from WT and BACHD mice at 2 and 12 months (insets are averages). There was a significant increase in the mean frequency of sIPSCs in BACHD FS neurons, mainly in the small amplitude events, compared with those of WTs at both 2 and 12 months but no difference in mean sIPSC amplitudes.

function induced by mutant HTT. More unexpected was the observation that inhibitory inputs onto PLTS interneurons were reduced. In contrast, the inhibitory input onto FS interneurons was increased in BACHD mice, suggesting that firing rates may be dampened. In a recent study, the role of striatal FS interneurons was examined in mice by selectively inhibiting their excitatory inputs, thereby reducing interneuron firing, which resulted in robust dystonia-like impairments (Gittis et al., 2011). It is tempting to speculate that increased inhibition of FS interneurons also leads to reduced firing rates and typical dystonia in HD. It is possible that selective inhibition of striatal PLTS and FS interneu- rons could ameliorate the HD behavioral phenotype. However, if release of SOM and NO is indeed neuroprotective, then activation of PLTS interneurons would be beneficial. The contrasting changes in interneuron excitability and inputs in HD are particularly intriguing. Considering the emerging and distinct roles of interneuron subtypes in striatal function, this imbalance, to our knowledge the first ever reported in a pathological condition, could have profound effects on motor function.

What is the possible consequence of prominent increases in GABA synaptic activity in indirect pathway MSNs? We and others have demonstrated that cells of the indirect pathway receive 
more glutamatergic inputs and are more excitable than cells of the direct pathway (Kreitzer and Malenka, 2007; Cepeda et al., 2008; Gertler et al., 2008). In genetic HD mouse models excitatory activity is increased early and progressively decreases (Graham et al., 2009; Joshi et al., 2009; André et al., 2011b). It is tempting to speculate that the increase in inhibitory synaptic activity is an attempt to cope with the early increased excitation. The increase in striatal inhibitory activity affects both MSN populations but becomes more pronounced in MSNs of the indirect pathway (André et al., 2011a). In agreement, this is the cell population that appears to be most affected in HD (Reiner et al., 1988; Albin et al., 1992).

Although the present study concentrated on the basic striatal microcircuit (Tepper et al., 2004) to uncover the primary sources of internal inhibition in the striatum, other possibilities should be considered. Thus, we cannot rule out that extrinsic sources could also play a role. For example, a recent study has emphasized the existence of long-range axonal projections from cortical interneurons (Clancy et al., 2010) and there is evidence that the corticostriatal pathway contains a subset of PV-positive axons mainly from pyramidal but also from nonpyramidal neurons (Jinno and Kosaka, 2004). In addition, arkypallidal neurons from the external globus pallidus send projections back to the striatum that connect to both interneurons and MSNs (Mallet et al., 2012). Also, using optogenetic techniques that selectively target tyrosine hydroxylase-positive substantia nigra neurons, a recent study demonstrated that these neurons can release GABA in addition to dopamine (Tritsch et al., 2012). Furthermore, we did not examine the small population of tyrosine hydroxylase-positive interneurons intrinsic to the striatum (Huot and Parent, 2007). At least one subtype of these interneurons fires spontaneously and can elicit GABAergic responses in MSNs (Ibáñez-Sandoval et al., 2010; Masuda et al., 2011) and could also contribute to increased GABA synaptic activity in HD. Finally, the precise mechanisms linking altered GABA inhibition and mutant HTT remain to be uncovered.

In conclusion, the present findings provide strong evidence that there are different sources for the increased GABA activity of indirect pathway MSNs in HD. The most likely sources are feedforward inhibition from FS and PLTS interneurons. These two types of interneurons provide differential inhibitory input. The PLTS interneurons appear to be the source of increased GABAergic spontaneous synaptic events while the FS interneurons, when activated, appear to be the source of larger GABAmediated synaptic responses. In addition, the higher bidirectional MSN connectivity may be another source but this source seems to be more restricted to direct pathway MSNs.

\section{References}

Albin RL, Reiner A, Anderson KD, Dure LS 4th, Handelin B, Balfour R, Whetsell WO Jr, Penney JB, Young AB (1992) Preferential loss of striato-external pallidal projection neurons in presymptomatic Huntington's disease. Ann Neurol 31:425-430. CrossRef Medline

André VM, Fisher YE, Levine MS (2011a) Altered balance of activity in the striatal direct and indirect pathways in mouse models of Huntington's disease. Front Syst Neurosci 5:46. Medline

André VM, Cepeda C, Fisher YE, Huynh M, Bardakjian N, Singh S, Yang XW, Levine MS (2011b) Differential electrophysiological changes in striatal output neurons in Huntington's disease. J Neurosci 31:1170-1182. CrossRef Medline

Bazzett T, Geiger A, Coppola B, Albin R (1997) The neuronal NOS inhibitor L-MIN, but not 7-NINA, reduces neurotoxic effects of chronic intrastriatal administration of quinolinic acid. Brain Res 775:229-232. CrossRef Medline

Brickley SG, Mody I (2012) Extrasynaptic GABA(A) receptors: their func- tion in the CNS and implications for disease. Neuron 73:23-34. CrossRef Medline

Centonze D, Rossi S, Prosperetti C, Tscherter A, Bernardi G, Maccarrone M, Calabresi P (2005) Abnormal sensitivity to cannabinoid receptor stimulation might contribute to altered gamma-aminobutyric acid transmission in the striatum of R6/2 Huntington's disease mice. Biol Psychiatry 57:1583-1589. CrossRef Medline

Cepeda C, Hurst RS, Calvert CR, Hernández-Echeagaray E, Nguyen OK, Jocoy E, Christian LJ, Ariano MA, Levine MS (2003) Transient and progressive electrophysiological alterations in the corticostriatal pathway in a mouse model of Huntington's disease. J Neurosci 23:961-969. Medline

Cepeda C, Starling AJ, Wu N, Nguyen OK, Uzgil B, Soda T, André VM, Ariano MA, Levine MS (2004) Increased GABAergic function in mouse models of Huntington's disease: reversal by BDNF. J Neurosci Res 78: 855-867. CrossRef Medline

Cepeda C, Wu N, André VM, Cummings DM, Levine MS (2007) The corticostriatal pathway in Huntington's disease. Prog Neurobiol 81:253-271. CrossRef Medline

Cepeda C, André VM, Yamazaki I, Wu N, Kleiman-Weiner M, Levine MS (2008) Differential electrophysiological properties of dopamine D1 and D2 receptor-containing striatal medium-sized spiny neurons. Eur J Neurosci 27:671-682. CrossRef Medline

Clancy B, Defelipe J, Espinosa A, Fairén A, Jinno S, Kanold P, Luhmann HJ, Rockland KS, Tamamaki N, Yan XX (2010) Cortical GABAergic neurons: stretching it remarks, main conclusions and discussion. Front Neuroanat 4:7. Medline

Cummings DM, André VM, Uzgil BO, Gee SM, Fisher YE, Cepeda C, Levine MS (2009) Alterations in cortical excitation and inhibition in genetic mouse models of Huntington's disease. J Neurosci 29:10371-10386. CrossRef Medline

Cummings DM, Cepeda C, Levine MS (2010) Alterations in striatal synaptic transmission are consistent across genetic mouse models of Huntington's disease. ASN Neuro 2:e00036. Medline

Cummings DM, Alaghband Y, Hickey MA, Joshi PR, Hong SC, Zhu C, Ando TK, André VM, Cepeda C, Watson JB, Levine MS (2012) A critical window of CAG repeat-length correlates with phenotype severity in the R6/2 mouse model of Huntington's disease. J Neurophysiol 107:677-691. CrossRef Medline

Czubayko U, Plenz D (2002) Fast synaptic transmission between striatal spiny projection neurons. Proc Natl Acad Sci U S A 99:15764-15769. CrossRef Medline

Deckel AW (2001) Nitric oxide and nitric oxide synthase in Huntington's disease. J Neurosci Res 64:99-107. CrossRef Medline

Dehorter N, Guigoni C, Lopez C, Hirsch J, Eusebio A, Ben-Ari Y, Hammond C (2009) Dopamine-deprived striatal GABAergic interneurons burst and generate repetitive gigantic IPSCs in medium spiny neurons. J Neurosci 29:7776-7787. CrossRef Medline

Dvorzhak A, Semtner M, Faber DS, Grantyn R (2013) Tonic mGluR5/CB1dependent suppression of inhibition as a pathophysiological hallmark in the striatum of mice carrying a mutant form of huntingtin. J Physiol 591:1145-1166. CrossRef Medline

Galarraga E, Vilchis C, Tkatch T, Salgado H, Tecuapetla F, Perez-Rosello T, Perez-Garci E, Hernandez-Echeagaray E, Surmeier DJ, Bargas J (2007) Somatostatinergic modulation of firing pattern and calcium-activated potassium currents in medium spiny neostriatal neurons. Neuroscience 146:537-554. CrossRef Medline

Gertler TS, Chan CS, Surmeier DJ (2008) Dichotomous anatomical properties of adult striatal medium spiny neurons. J Neurosci 28:1081410824. CrossRef Medline

Gittis AH, Nelson AB, Thwin MT, Palop JJ, Kreitzer AC (2010) Distinct roles of GABAergic interneurons in the regulation of striatal output pathways. J Neurosci 30:2223-2234. CrossRef Medline

Gittis AH, Leventhal DK, Fensterheim BA, Pettibone JR, Berke JD, Kreitzer AC (2011) Selective inhibition of striatal fast-spiking interneurons causes dyskinesias. J Neurosci 31:15727-15731. CrossRef Medline

Graham RK, Pouladi MA, Joshi P, Lu G, Deng Y, Wu NP, Figueroa BE, Metzler M, André VM, Slow EJ, Raymond L, Friedlander R, Levine MS, Leavitt BR, Hayden MR (2009) Differential susceptibility to excitotoxic stress in YAC128 mouse models of Huntington disease between initiation and progression of disease. J Neurosci 29:2193-2204. CrossRef Medline

Gray M, Shirasaki DI, Cepeda C, André VM, Wilburn B, Lu XH, Tao J, Yamazaki I, Li SH, Sun YE, Li XJ, Levine MS, Yang XW (2008) Full- 
length human mutant huntingtin with a stable polyglutamine repeat can elicit progressive and selective neuropathogenesis in BACHD mice. J Neurosci 28:6182-6195. CrossRef Medline

Guzman JN, Hernández A, Galarraga E, Tapia D, Laville A, Vergara R, Aceves J, Bargas J (2003) Dopaminergic modulation of axon collaterals interconnecting spiny neurons of the rat striatum. J Neurosci 23:8931-8940. Medline

Hodgson JG, Agopyan N, Gutekunst CA, Leavitt BR, LePiane F, Singaraja R, Smith DJ, Bissada N, McCutcheon K, Nasir J, Jamot L, Li XJ, Stevens ME, Rosemond E, Roder JC, Phillips AG, Rubin EM, Hersch SM, Hayden MR (1999) A YAC mouse model for Huntington's disease with full-length mutant huntingtin, cytoplasmic toxicity, and selective striatal neurodegeneration. Neuron 23:181-192. CrossRef Medline

Huot P, Parent A (2007) Dopaminergic neurons intrinsic to the striatum. J Neurochem 101:1441-1447. CrossRef Medline

Ibáñez-Sandoval O, Tecuapetla F, Unal B, Shah F, Koós T, Tepper JM (2010) Electrophysiological and morphological characteristics and synaptic connectivity of tyrosine hydroxylase-expressing neurons in adult mouse striatum. J Neurosci 30:6999-7016. CrossRef Medline

Jinno S, Kosaka T (2004) Parvalbumin is expressed in glutamatergic and GABAergic corticostriatal pathway in mice. J Comp Neurol 477:188-201. CrossRef Medline

Johnson MA, Rajan V, Miller CE, Wightman RM (2006) Dopamine release is severely compromised in the R6/2 mouse model of Huntington's disease. J Neurochem 97:737-746. CrossRef Medline

Joshi PR, Wu NP, André VM, Cummings DM, Cepeda C, Joyce JA, Carroll JB, Leavitt BR, Hayden MR, Levine MS, Bamford NS (2009) Agedependent alterations of corticostriatal activity in the YAC128 mouse model of Huntington disease. J Neurosci 29:2414-2427. CrossRef Medline

Kawaguchi Y, Wilson CJ, Augood SJ, Emson PC (1995) Striatal interneurones: chemical, physiological and morphological characterization. Trends Neurosci 18:527-535. CrossRef Medline

Kita H (1993) GABAergic circuits of the striatum. Prog Brain Res 99:51-72. CrossRef Medline

Klapstein GJ, Fisher RS, Zanjani H, Cepeda C, Jokel ES, Chesselet MF, Levine MS (2001) Electrophysiological and morphological changes in striatal spiny neurons in R6/2 Huntington's disease transgenic mice. J Neurophysiol 86:2667-2677. Medline

Koós T, Tepper JM (1999) Inhibitory control of neostriatal projection neurons by GABAergic interneurons. Nat Neurosci 2:467-472. CrossRef Medline

Koós T, Tepper JM, Wilson CJ (2004) Comparison of IPSCs evoked by spiny and fast-spiking neurons in the neostriatum. J Neurosci 24: 7916-7922. CrossRef Medline

Kreitzer AC (2009) Physiology and pharmacology of striatal neurons. Annu Rev Neurosci 32:127-147. CrossRef Medline

Kreitzer AC, Malenka RC (2007) Endocannabinoid-mediated rescue of striatal LTD and motor deficits in Parkinson's disease models. Nature 445: 643-647. CrossRef Medline

Laforet GA, Sapp E, Chase K, McIntyre C, Boyce FM, Campbell M, Cadigan BA, Warzecki L, Tagle DA, Reddy PH, Cepeda C, Calvert CR, Jokel ES, Klapstein GJ, Ariano MA, Levine MS, DiFiglia M, Aronin N (2001) Changes in cortical and striatal neurons predict behavioral and electrophysiological abnormalities in a transgenic murine model of Huntington's disease. J Neurosci 21:9112-9123. Medline

Levine MS, Cepeda C, Hickey MA, Fleming SM, Chesselet MF (2004) Genetic mouse models of Huntington's and Parkinson's diseases: illuminating but imperfect. Trends Neurosci 27:691-697. CrossRef Medline

Mallet N, Micklem BR, Henny P, Brown MT, Williams C, Bolam JP, Nakamura KC, Magill PJ (2012) Dichotomous organization of the external globus pallidus. Neuron 74:1075-1086. CrossRef Medline

Mangiarini L, Sathasivam K, Seller M, Cozens B, Harper A, Hetherington C, Lawton M, Trottier Y, Lehrach H, Davies SW, Bates GP (1996) Exon 1 of the HD gene with an expanded CAG repeat is sufficient to cause a progressive neurological phenotype in transgenic mice. Cell 87:493-506. CrossRef Medline
Marin O, Anderson SA, Rubenstein JL (2000) Origin and molecular specification of striatal interneurons. J Neurosci 20:6063-6076. Medline

Masuda M, Miura M, Inoue R, Imanishi M, Saino-Saito S, Takada M, Kobayashi K, Aosaki T (2011) Postnatal development of tyrosine hydroxylase mRNA-expressing neurons in mouse neostriatum. Eur J Neurosci 34:1355-1367. CrossRef Medline

Murphy-Nakhnikian A, Dorner JL, Fischer BI, Bower-Bir ND, Rebec GV (2012) Abnormal burst patterns of single neurons recorded in the substantia nigra reticulata of behaving 140 CAG Huntington's disease mice. Neurosci Lett 512:1-5. CrossRef Medline

Plotkin JL, Wu N, Chesselet MF, Levine MS (2005) Functional and molecular development of striatal fast-spiking GABAergic interneurons and their cortical inputs. Eur J Neurosci 22:1097-1108. CrossRef Medline

Raymond LA, André VM, Cepeda C, Gladding CM, Milnerwood AJ, Levine MS (2011) Pathophysiology of Huntington's disease: time-dependent alterations in synaptic and receptor function. Neuroscience 198:252-273. CrossRef Medline

Rebec GV, Conroy SK, Barton SJ (2006) Hyperactive striatal neurons in symptomatic Huntington R6/2 mice: variations with behavioral state and repeated ascorbate treatment. Neuroscience 137:327-336. CrossRef Medline

Reiner A, Albin RL, Anderson KD, D’Amato CJ, Penney JB, Young AB (1988) Differential loss of striatal projection neurons in Huntington disease. Proc Natl Acad Sci U S A 85:5733-5737. CrossRef Medline

Santhakumar V, Jones RT, Mody I (2010) Developmental regulation and neuroprotective effects of striatal tonic GABAA currents. Neuroscience 167:644-655. CrossRef Medline

Taverna S, van Dongen YC, Groenewegen HJ, Pennartz CM (2004) Direct physiological evidence for synaptic connectivity between medium-sized spiny neurons in rat nucleus accumbens in situ. J Neurophysiol 91:11111121. Medline

Taverna S, Ilijic E, Surmeier DJ (2008) Recurrent collateral connections of striatal medium spiny neurons are disrupted in models of Parkinson's disease. J Neurosci 28:5504-5512. CrossRef Medline

Tecuapetla F, Carrillo-Reid L, Guzmán JN, Galarraga E, Bargas J (2005) Different inhibitory inputs onto neostriatal projection neurons as revealed by field stimulation. J Neurophysiol 93:1119-1126. Medline

Tepper JM, Bolam JP (2004) Functional diversity and specificity of neostriatal interneurons. Curr Opin Neurobiol 14:685-692. CrossRef Medline

Tepper JM, Koós T, Wilson CJ (2004) GABAergic microcircuits in the neostriatum. Trends Neurosci 27:662-669. CrossRef Medline

Tepper JM, Wilson CJ, Koós T (2008) Feedforward and feedback inhibition in neostriatal GABAergic spiny neurons. Brain Res Rev 58:272-281. CrossRef Medline

Tepper JM, Tecuapetla F, Koós T, Ibáñez-Sandoval O (2010) Heterogeneity and diversity of striatal GABAergic interneurons. Front Neuroanat 4:150. Medline

The Huntington's Disease Collaborative Research Group (1993) A novel gene containing a trinucleotide repeat that is expanded and unstable on Huntington's disease chromosomes. Cell 72:971-983. CrossRef Medline

Tobin AJ, Signer ER (2000) Huntington's disease: the challenge for cell biologists. Trends Cell Biol 10:531-536. CrossRef Medline

Tritsch NX, Ding JB, Sabatini BL (2012) Dopaminergic neurons inhibit striatal output through non-canonical release of GABA. Nature 490:262-266. CrossRef Medline

Tunstall MJ, Oorschot DE, Kean A, Wickens JR (2002) Inhibitory interactions between spiny projection neurons in the rat striatum. J Neurophysiol 88:1263-1269. Medline

Tye KM, Deisseroth K (2012) Optogenetic investigation of neural circuits underlying brain disease in animal models. Nat Rev Neurosci 13:251-266. CrossRef Medline

Vonsattel JP, DiFiglia M (1998) Huntington disease. J Neuropathol Exp Neurol 57:369-384. CrossRef Medline

Yuen EY, Wei J, Zhong P, Yan Z (2012) Disrupted GABAAR trafficking and synaptic inhibition in a mouse model of Huntington's disease. Neurobiol Dis 46:497-502. CrossRef Medline 